\title{
Exceptional carbon uptake in European forests during the warm spring of 2007: a data-model analysis
}

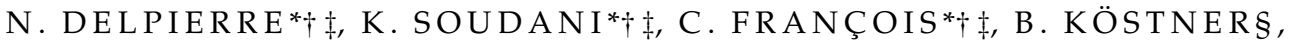

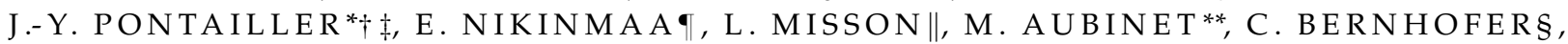

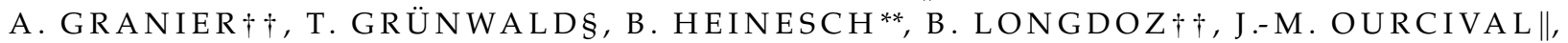 \\ S. RAMBAL $\|$, T. VESALA $\uparrow$ and E. DUFRE NE*† \\ *Univ. Paris-Sud, Laboratoire Ecologie Systématique et Evolution, UMR8079, Orsay F-91405, France, †CNRS, Orsay F-91405, \\ France, $\ddagger$ AgroParisTech, Paris, F-75231, §Department of Meteorology, Institute of Hydrology and Meteorology, Technische \\ Universität, Dresden, Germany, -Department of Physical Sciences, Helsinki, Finland, |CNRS, Centre d'Ecologie Fonctionnelle \\ et Evolutive, Montpellier, France, ${ }^{* *}$ Faculté Universitaire des Sciences Agronomiques, Gembloux, Belgium, ††INRA, Unité \\ d'Ecophysiologie Forestière, Champenoux, France
}

\begin{abstract}
Temperate and boreal forests undergo drastic functional changes in the springtime, shifting within a few weeks from net carbon (C) sources to net $C$ sinks. Most of these changes are mediated by temperature. The autumn 2006-winter 2007 record warm period was followed by an exceptionally warm spring in Europe, making spring 2007 a good candidate for advances in the onset of the photosynthetically active period. An analysis of a decade of eddy covariance data from six European forests stands, which encompass a wide range of functional types (broadleaf evergreen, broadleaf deciduous, needleleaf evergreen) and a wide latitudinal band (from $44^{\circ}$ to $62^{\circ} \mathrm{N}$ ), revealed exceptional fluxes during spring 2007. Gross primary productivity (GPP) of spring 2007 was the maximum recorded in the decade examined for all sites but a Mediterranean evergreen forest (with a +40 to $+130 \mathrm{gC} \mathrm{m}^{-2}$ anomaly compared with the decadal mean over the January-May period). Total ecosystem respiration (TER) was also promoted during spring 2007, though less anomalous than GPP (with a +17 to $+93 \mathrm{gC} \mathrm{m}^{-2}$ anomaly over 5 months), leading to higher net uptake than the long-term mean at all sites $\left(+12\right.$ to $+79 \mathrm{gC} \mathrm{m}^{-2}$ anomaly over 5 months). A correlative analysis relating springtime $\mathrm{C}$ fluxes to simple phenological indices suggested spring $C$ uptake and temperatures to be related. The CASTANEA process-based model was used to disentangle the seasonality of climatic drivers (incoming radiation, air and soil temperatures) and biological drivers (canopy dynamics, thermal acclimation of photosynthesis to low temperatures) on spring $\mathrm{C}$ fluxes along the latitudinal gradient. A sensitivity analysis of model simulations evidenced the roles of (i) an exceptional early budburst combined with elevated air temperature in deciduous sites, and (ii) an early relief of winter thermal acclimation in coniferous sites for the promotion of 2007 spring assimilation.
\end{abstract}

Keywords: European forests, functional drivers, net carbon uptake, process-based model, spring

Received 30 May 2008; revised version received 30 August 2008 and accepted 13 October 2008

Introduction

Springtime phenological phases are recognized as one of the major determinants of the annual carbon (C) balance of temperate and boreal forest stands (Goulden et al., 1996; Berninger, 1997; Black et al., 2000; Barr et al.,

Correspondence: N. Delpierre, Univ. Paris-Sud, Laboratoire Ecologie Systématique et Evolution, UMR8079, Orsay F-91405,

France, e-mail: nicolas.delpierre@u-psud.fr

Journal compilation (C) 2009 Blackwell Publishing Ltd

No claim to original US government works
2007), and further modulate the $C$ balance at the continental scale (Keeling et al., 1996; Randerson et al., 1999). From temperate to boreal latitudes, in the springtime (hereafter defined as January-May), forest ecosystems undergo a range of functional changes that drastically affect their interactions with the atmosphere, either in terms of energy or C exchanges (Schmid et al., 2000; Wilson \& Baldocchi, 2000; Blanken et al., 2001).

For deciduous species, these functional changes include bud break, leaf expansion (Davi et al., 2008) and 
subsequent canopy development which, together with the assembly of the photosynthetic apparatus (Wilson et al., 2000; Grassi et al., 2005) turn deciduous trees from net $C$ providers into net $C$ withdrawers from the atmosphere within a few weeks. Experimental evidence and empirical modelling underline the influence of temperature on the progress of the ontogenic stages involved (see Sarvas, 1972; Chuine, 2000; Schaber \& Badeck, 2003 for budburst, Davi et al., 2008 for leaf mass per area).

In evergreen stands, leaf longevity dampens the seasonal variability of leaf area, so that structural changes in spring affect less drastically the canopyatmosphere exchanges. Evergreen species adapted to live at low winter temperatures have evolved mechanisms of stress prevention: (i) frost hardening, which prevents frost damage of living tissues and (ii) downregulation of photosynthetic capacity, which prevents photo-oxidative damages at low temperatures (Öquist \& Huner, 2003). These coincident mechanisms are triggered by the occurrence of low temperatures (Leinonen, 1996; Repo et al., 2006), and relaxed given above-freezing temperatures in spring (Mäkelä et al., 2004; Sevanto et al., 2006; Kolari et al., 2007), though potentially reversed during spring frost events (Leinonen, 1996; Bergh et al., 1998).

The co-occurrence of photosynthetic capacity onset in deciduous trees or upregulation in conifers with high radiation levels, favourable temperatures, low evaporative demand and nonlimiting soil water rapidly yields high values of gross primary productivity (GPP) in the spring (Falge et al., 2002). Although autotrophic and heterotrophic respiration processes are promoted during spring warming (Stockfors \& Linder, 1998; Epron et al., 2001; Damesin et al., 2002), the seasonality of total ecosystem respiration (TER) is dampened compared with that of GPP in temperate and boreal forests, which leads to a strong dependency of the springtime net ecosystem productivity (NEP) on GPP (Falge et al., 2002).

The autumn 2006-winter 2007 period has been identified as likely the warmest for more than 500 years in Europe, with +1.7 and $+2.4 \mathrm{~K}$ increases in autumn 2006 and winter 2007, respectively, compared with the 1961-1990 means at the continental scale (Luterbacher et al., 2007). These extreme temperatures were associated with delayed autumn senescence in 2006 (Piao et al., 2008; Delpierre et al., in press) and early occurrence of springtime 2007 phenophases throughout Europe (Table 1).

In accordance with our knowledge of springtime processes affecting $\mathrm{C}$ exchanges in forest stands and the observation of early occurrence of spring phenological events, high temperatures observed in spring 2007 were likely to have impacted $\mathrm{C}$ exchanges between European forest ecosystems and the atmosphere.

In the first part of this study, we took advantage of the CARBOEUROPE-IP database to conduct a data analysis aimed at illustrating the impact of the warm spring of 2007 on C fluxes across Europe (from southern France to Finland) for three forest functional types. We then used the process-based SVAT/growth model CASTANEA to disentangle for each study site the influences of climatic and biological factors on the determinism of spring GPP, TER and NEP, placing emphasis on the warm spring of 2007.

\section{Methodology}

\section{Study sites and flux data}

Six sites involved in the CARBOEUROPE-IP were selected for this study. These sites encompass three forest functional types (namely evergreen broadleaf, evergreen coniferous and broadleaf deciduous) along a broad latitudinal gradient $\left(44-62^{\circ} \mathrm{N}\right)$. At all sites, meteorological data and net $C$ and water exchange measurements according to the eddy covariance technique are routinely acquired on a half-hourly basis, following the standard methodology recommended by Aubinet et al. (2000). All selected sites except the FRFon forest have been continuously run for $8-11$ years. The FRFon site was established more recently (three site-years), but was added to the present dataset given that it was the only one monitoring a sessile Oak forest [Quercus petraea (Matt.) Liebl.], a species widely spread across Europe. A brief description of the main characteristics of the six stands and further references are provided in Table 2.

All available continuous data over the January 1997June 2007 period were quality-controlled, gap-filled and partitioned into GPP and TER, according to CARBOEUROPE database standards (Reichstein et al., 2005; Papale et al., 2006). For the FRFon site, instrumented with an open-path IRGA (LI-7500, Licor, Lincoln, NE), the density correction term was computed according to Burba et al. (2008), in order to take into account the open-path analyser self-heating. A site-specific $u^{*}$ threshold value was used to filter out data acquired under stable conditions (Table 2). Parameter fitting for flux partitioning was performed according to the short-term exponential method (Reichstein et al., 2005).

\section{Construction of phenological indices}

We assessed the ability of three simple phenological indices to predict the interannual variability of springtime GPP and NEP sums. Springtime was defined as the period extending from January to May, a period that 


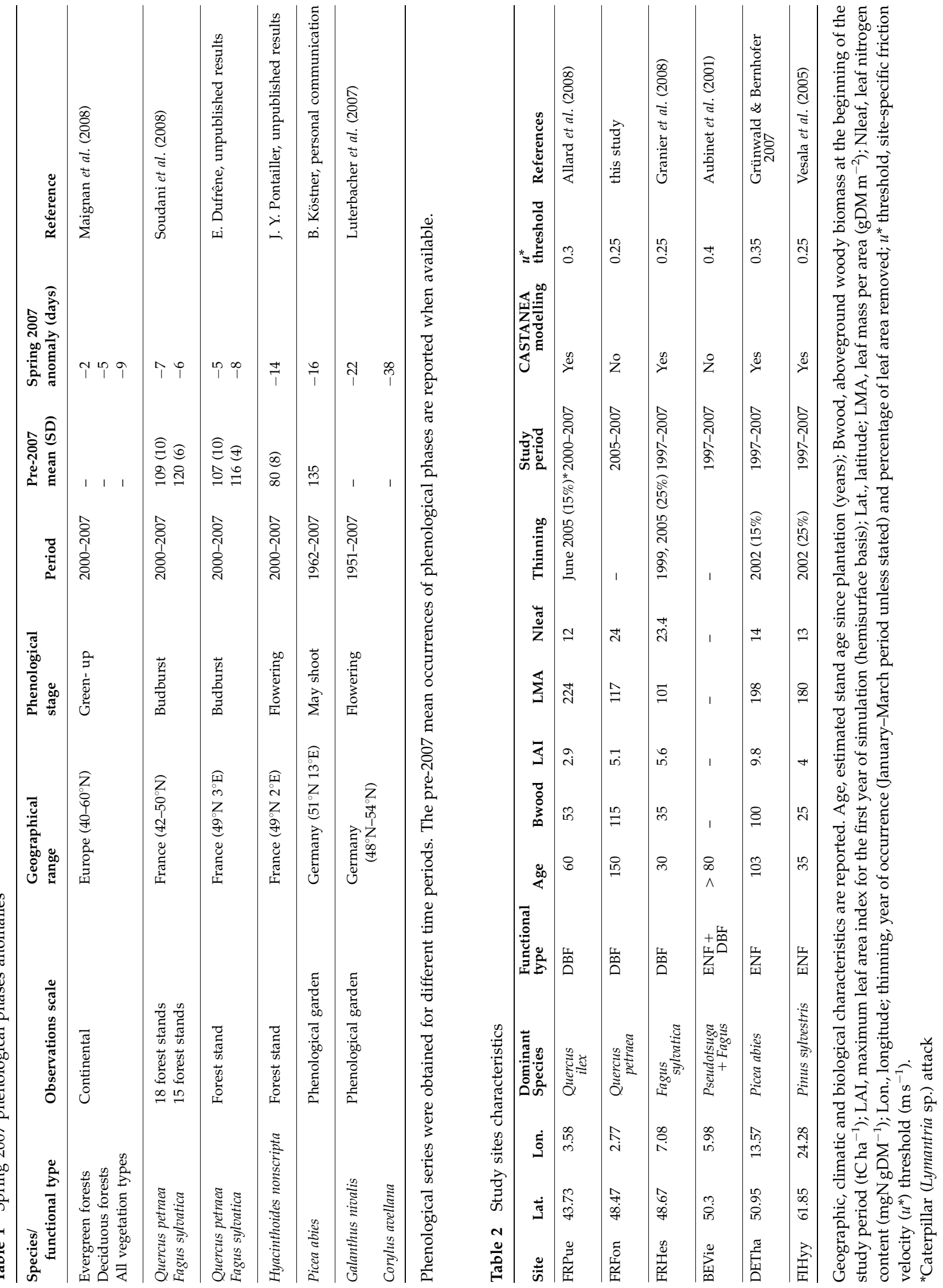




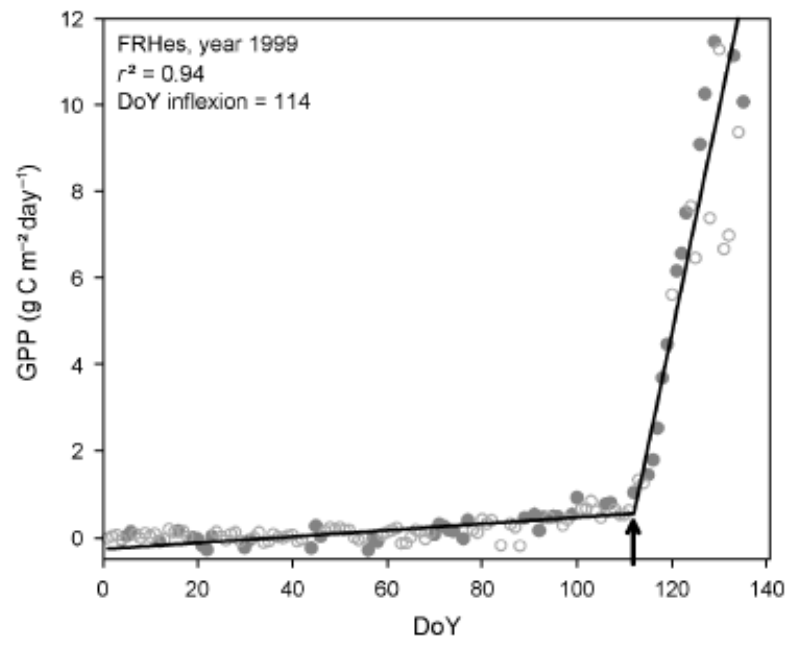

Fig. 1 A sharp rise in gross primary productivity (GPP) identifies the start of the growing season in deciduous forests. A piecewise linear model (line) was fitted to the GPP time series measured on clear days. Disks, denote clear days (ratio of incoming to exoatmospheric radiation $>0.4$ ). Circles denote cloudy days, not considered for fitting the piecewise model. The example drawn is for the year 1999 at the FRHes Beech forest. The arrow marks the initiation of the photosynthetically active season.

encompasses the whole range of winter/spring functional changes of interest in this paper.

The first phenological index was the sum of springtime positive temperatures. The second phenological index was the onset of the net carbon uptake period (CUP), defined as the day of NEP zero-crossing during the source/sink transition period. Following Baldocchi et al. (2005), we determined the NEP zero-crossing date by regression of daily NEP on day of year, using a 30day data subset from the source-sink transition period. The third phenological index was constructed for the sole deciduous sites and consisted of the first day of the photosynthetically active season. This date was determined through a piecewise two-segment linear model fitted to the GPP time series for clear days. The junction point of the piecewise model was considered as the start of the active season in deciduous sites (Fig. 1).

\section{Modelling of the $C$ balance}

The process-based SVAT/growth model CASTANEA (Dufrêne et al., 2005) was used to simulate $C$ and water fluxes and stocks at four of the study sites (FRPue, FRHes, DETha and FIHyy, Table 2). No simulation was performed for the mixed BEVie forest, as CASTANEA is designed for monospecific stands. Simulations are not reported for the FRFon site, as the short period of measurements and simulations (3 years) did not allow for the application of the method developed to disentangle the influences of climatic and biological drivers on C fluxes (see infra).

For this study, we relied on the original version of the CASTANEA model (Dufrêne et al., 2005). CASTANEA SVAT and growth modules have thoroughly been validated on a range of monospecific, even-aged forest ecosystems for 1-year periods at temperate latitudes (Davi et al., 2005, 2006; Le Maire et al., 2005).

We implemented to the original version of CASTANEA a photosynthesis thermal acclimation model (Bergh et al., 1998; Hänninen \& Hari, 2002), in order to simulate the winter downregulation of photosynthetic capacity occurring in coniferous evergreen sites exposed to low winter temperatures. Photosynthetic acclimation takes the form of the AccP factor, varying in the $\left[\mathrm{AccP}_{\min } ; \mathrm{AccP}_{\max }\right]$ interval, and impacts potential carboxylation capacity $\left(V_{\text {cmax }}\right)$, potential electron flow $\left(J_{\max }\right)$ and quantum yield as a multiplicative modifier. In autumn, first frosts cause a rapid decline of AccP from the maximal summer value $\left(\mathrm{Acc}_{\max }=1\right)$. AccP remains at its minimal value $\left(\mathrm{AccP}_{\min }=0.15\right)$ for most of the winter. In spring, AccP progressively tends towards one $\left(\mathrm{AccP}_{\max }=1\right)$ as daily mean temperature increases, though AccP potentially reverses towards $\mathrm{AccP}_{\min }$ when frosts occur. The critical degree-day (d.d.) sum for AccP to equal $\mathrm{AccP}_{\max }$ was 180 d.d. in Pinus (Hänninen \& Hari, 2002) and was set to 150 d.d. to allow for a realistic progress of photosynthesis in Picea. For the evergreen broadleaf species Quercus ilex, winter acclimation of the photosynthetic apparatus has not been modelled, though results from field studies suggest that photoprotective mechanisms may impair assimilation during cold periods for this species (e.g. Oliveira \& Peñuelas, 2000). Following several authors (e.g. Suni et al., 2003a; Mäkelä et al., 2008), no influence of soil temperature on spring photosynthesis resumption was accounted for in the model.

The simulation of budburst in deciduous stands is performed in CASTANEA through a spring warming model (Dufrêne et al., 2005), which provides a prediction accuracy of ca. 5 days (e.g. Schaber \& Badeck, 2003). As the completion of our objectives depended on the reliability of the model estimates, we could not afford this degree of error in the predicted budburst date. We instead used the inflexion point method (Fig. 1) as a benchmark for simulating budburst, forcing budburst to occur 4 days before the observed inflexion in diurnal NEP.

For the purpose of the present study, C and water balance modelling was performed from 1 January 1997 to 31 May 2007 for three sites (FIHyy, DETha and FRHes) and from 1 January 2001 to 31 May 2007 for the FRPue site. Simulations over the whole period of 
interest (i.e. not only spring) were necessary to insure continuity in the simulation of the state variables (wood biomasses, soil C pools, soil water balance, etc.). C contents of the heterotrophic pools were initiated to satisfy steady state at the end of the run. Only simulations for the springtime (January-May) period were analysed in the following work.

\section{Model validation}

A necessary step before the use of the model as a disentangling tool is the validation of simulated fluxes. Model validation was performed for two time scales. We based the model validation on the goodness of representation of (i) daily sums, which assessed the model's ability to reproduce the seasonal pattern of the measured flux and its day-to-day variations, and (ii) semi-annual (spring) sums, which assessed the overall representation of integrated processes. In both cases, model accuracy was assessed through comparison of simulated and measured diurnal NEP (NEPd). We therefore based the model validation on the highest quality measured data and avoided consideration of potentially biased eddy covariance measurements acquired under stable nightly conditions (see Falge et al., 2003; Davi et al., 2006 for analogous model validation protocols).

\section{Springtime patterns of $C$ fluxes drivers}

We introduce a novel method to illustrate for each study site the pattern of influence of climatic and biological drivers on GPP, TER and NEP. This method aims to express for each flux, on each day of year, the proportion of interannual flux variance explained by potential climatic or biological drivers.

We identified as potential drivers of springtime $\mathrm{C}$ fluxes two climatic drivers (incoming radiation, $\mathrm{Rg}$, and ecosystem temperature, $T_{\text {eco }}$ ) and two biological drivers (canopy dynamics CDyn, and photosynthetic acclimation factor, AccP). The influences of these factors on modelled processes are summarized in Table 3. Climatic drivers exert instantaneous influences in the model calculations. Conversely, the dynamics of biological drivers, which are simulated by CASTANEA through combined temperature sums (Bergh et al., 1998; Dufrêne et al., 2005), reflect the long-term integrated influences of thermal constraints. We do not considered air and soil temperatures as independent climatic drivers, as these variables are intimately correlated. It can be seen from Table 3 that in the model, TER is influenced by both soil and air temperature, and that no influence of soil temperature is accounted for to simulate GPP. Soil temperature is simulated in the model at three depths $(-5,-15$ and $-30 \mathrm{~cm})$ through a simple biophysical model (Paul et al., 2004) forced by air temperature and modulated by canopy and soil characteristics. We could not use measured soil temperature as a forcing variable because the data were only sporadically available at all sites for the period of interest. Comparison of modelled and measured soil temperatures when available where excellent at all sites (with $r^{2}>0.90$, not shown).

For the sake of completeness, we verified that soil water content (typically nonlimiting during springtime)

Table 3 Summary of the influences of scoped climatic and biological drivers on modelled processes

\begin{tabular}{|c|c|c|c|}
\hline Driver & Symbol & Influence on modelled GPP & Influence on modelled TER \\
\hline \multicolumn{4}{|l|}{ Climatic drivers } \\
\hline Incoming radiation & $\operatorname{Rg}$ & Modulates electron transport rate & - \\
\hline \multicolumn{4}{|l|}{ Ecosystem temperature } \\
\hline \multirow[t]{2}{*}{ Teco } & $T_{\text {air }}$ & $\begin{array}{l}\text { Modulates electron transport and } \\
\text { carboxylation rates }\end{array}$ & $\begin{array}{l}\text { Modulates aboveground maintenance } \\
\text { respiration }\end{array}$ \\
\hline & $T_{\text {soil }}$ & - & $\begin{array}{l}\text { Modulates roots maintenance respiration } \\
\text { and heterotrophic respiration }\end{array}$ \\
\hline \multicolumn{4}{|l|}{ Biological drivers } \\
\hline Canopy dynamics & CDyn & $\begin{array}{l}\text { Defines the instant amount of } \\
\text { photosynthetically active area }\end{array}$ & $\begin{array}{l}\text { Scales with canopy growth and dark } \\
\text { respiration }\end{array}$ \\
\hline $\begin{array}{l}\text { Photosynthesis acclimation } \\
\text { factor }\end{array}$ & $\mathrm{AccP}$ & $\begin{array}{l}\text { Reduces potential carboxylation and } \\
\text { electron transport rates at freezing } \\
\text { temperatures }\end{array}$ & - \\
\hline
\end{tabular}

Only direct effects in the model are reported.

Accp, photosynthesis thermal acclimation factor; CDyn, canopy dynamics; GPP, Gross primary productivity; Rg, global radiation; $T_{\text {air }}$ air temperature; $T_{\text {soil, }}$ soil temperature; TER, total ecosystem respiration. 
Table 4 Simulation sets description

\begin{tabular}{|c|c|c|c|c|c|c|c|c|c|}
\hline \multicolumn{5}{|c|}{ Seasonal patterns of flux drivers } & \multicolumn{5}{|c|}{ Relative anomalies computation } \\
\hline Simulation & $T_{\text {eco }}$ & $\operatorname{Rg}$ & $\mathrm{AccP}$ & CDyn & Simulation & $T_{\text {eсо }}$ & $\operatorname{Rg}$ & AccP & CDyn \\
\hline$f_{\text {ref }}$ & $\mathrm{v}$ & $\mathrm{v}$ & $\mathrm{v}$ & $\mathrm{v}$ & $f_{\text {ref }}$ & $\mathrm{v}$ & $\mathrm{v}$ & $\mathrm{v}$ & $\mathrm{v}$ \\
\hline$f 1$ & $\mathrm{v}$ & - & - & - & $g 1$ & - & $\mathrm{v}$ & $\mathrm{v}$ & $\mathrm{v}$ \\
\hline$f 2$ & - & $\mathrm{v}$ & - & - & $g 2$ & $\mathrm{v}$ & - & $\mathrm{v}$ & $\mathrm{v}$ \\
\hline$f 3$ & - & - & $\mathrm{v}$ & - & $g 3$ & $\mathrm{v}$ & $\mathrm{v}$ & - & $\mathrm{v}$ \\
\hline$f 4$ & - & - & - & $\mathrm{v}$ & $g 4$ & $\mathrm{v}$ & $\mathrm{v}$ & $\mathrm{v}$ & - \\
\hline
\end{tabular}

v, climatic (Teco, Rg) or biological (AccP, CDyn) factor allowed to vary during the simulation. -, climatic or biological factor forced to its mean annual pattern for the duration of the simulation.

The first simulation set was used to derive the springtime pattern of limiting drivers [Eqn (1)]. The second simulation set was used to quantify the influences of drivers on 2007 fluxes sums [Eqn (3)].

Accp, photosynthesis thermal acclimation factor; CDyn, canopy dynamics; Rg, global radiation; $T_{\text {eco, }}$ ecosystem temperature.

had no impact on the variations of GPP, TER or NEP at any site during the considered January-May period (not shown). We did not consider wood biomass or soil $\mathrm{C}$ mass as potential drivers of $\mathrm{C}$ fluxes during spring. As state variables, both integrate on a given date the influence of preceding (from the past half-hour to the past 10 years in the model) climatic conditions, biological processes and possibly anthropic disturbances (thinning), so that their influences do not solely reflect the processes at stake during spring.

The deconvolution pattern of climatic and biological drivers influences is based on the reconstruction of the originally simulated flux, obtained under full variability of the four climatic and biological factors (termed $f_{\text {ref }}$ in Table 4), as a combination of partially forced simulations (termed $f_{1}-f_{4}$ in Table 4 ). Under partially forced simulations $\left(f_{1}-f_{4}\right)$, the sole factor of interest was allowed to vary freely (i.e. according to measurements for climatic factors, or following original simulations for biological factors), while all other factors were forced to their mean patterns (taking on day of year $d$ their mean value for that day of year over all study years). For each GPP, TER and NEP flux, on each day $d$ of the springtime period (DoY 1-151) we wrote the flux combination as a multiple linear regression (MLR) model, such as

$$
f_{\text {ref }}(d)=\sum_{i=1}^{4}\left[\beta_{i}(d) \times f_{i}(d)\right]+\varepsilon
$$

where $f_{\text {ref }}$ represents the normalized (centred-reduced) flux simulated under full drivers variabilities; $f_{i}$ the normalized flux obtained under partial forcing (i.e. the sole factor $i$ is free to vary, Table 4); $\beta_{i}$ the standard partial regression coefficient associated with the $f_{i}$ flux; and $\varepsilon$ the error term of the MLR model.

The objective of Eqn (1) was to determine for each day $d$ the influence of the $i$ th driver on flux variability. We sampled the simulated dependent $\left(f_{\text {ref }}\right)$ and indepen- dent $\left(f_{i}\right)$ variables on day $d$, plus 3 days before and 3 days after, therefore considering local variability around the day of interest. We extended the sampling to all occurrences of the window of interest (centred on day $d$ ) over all simulation years (i.e. considering years as repetitions), therefore considering interannual variability. For each day $d$, this resulted in a sampling size of 7 points per year multiplied by $n$ years $(n=11$ for most sites, Table 2) for each variable in the MLR model. The standard partial regression coefficient $\left[\beta_{i}(d)\right]$ associated with each $f_{i}(d)$ flux therefore indicates the signed proportion of the flux variability under the influence of the $i$ th factor of interest.

Owing to the potential correlation between predictor variables $\left[f_{i}\right.$ in Eqn (1)], multiple regression [Eqn (1)] was processed using a selective stepwise approach. The inclusion $P$-value for a new predictor variable to enter the MLR was set to $P<10^{-4}$. Such a strict criterion was used to allow only independent variables as predictors.

The proportion of flux $\Phi(\Phi=$ GPP, TER or NEP) interannual variance on day $d$ explained by the $i$ th factor $\left[e_{\Phi_{, i}}(d)\right]$ was quantified as the ratio of the squared magnitudes of the $\beta_{i}(d)$ standard partial regression coefficients, scaled by the squared multiple correlation coefficient $\left(R^{2}\right)$ of the multiple regression, such as

$$
\begin{aligned}
& e_{\Phi, i}(d)=\frac{\beta_{i}(d)^{2}}{\sum_{i=1}^{4} \beta_{i}(d)^{2}} \times R^{2}(d), \\
& \text { so that } \sum_{i=1}^{4} e_{\Phi, i}(d)=R^{2}(d) .
\end{aligned}
$$

\section{Sensitivity of the 2007 springtime GPP and TER sums}

We calculated the influence of single climatic and biological drivers on springtime annual sums for GPP and TER fluxes. For the $\Phi$ flux (GPP or TER), the annual 
Table 5 Anomalies of air temperature and carbon fluxes for spring 2007

\begin{tabular}{|c|c|c|c|c|c|c|c|c|c|c|c|c|c|c|c|c|c|}
\hline \multirow[b]{2}{*}{ Site } & \multirow[b]{2}{*}{ Period } & \multicolumn{4}{|c|}{ Air temperature } & \multicolumn{4}{|l|}{ GPP } & \multicolumn{4}{|l|}{ TER } & \multicolumn{4}{|l|}{ NEP } \\
\hline & & Mean & $\mathrm{SD}$ & $\Delta T$ & $\begin{array}{l}\text { Rank } \\
07\end{array}$ & Mean & SD & $\triangle \mathrm{GPP}$ & $\begin{array}{l}\text { Rank } \\
07\end{array}$ & Mean & $\mathrm{SD}$ & $\triangle \mathrm{TER}$ & $\begin{array}{l}\text { Rank } \\
07\end{array}$ & Mean & $\mathrm{SD}$ & $\triangle \mathrm{NEP}$ & $\begin{array}{l}\text { Rank } \\
07\end{array}$ \\
\hline FRPue & 2001-2007 & 9.8 & 0.7 & +1.6 & $1 / 7$ & 559 & 87 & +63 & $2 / 7$ & 373 & 73 & +17 & $4 / 7$ & 186 & 30 & +45 & $2 / 7$ \\
\hline FRFon $\dagger$ & 2005-2007 & 8.4 & 0.6 & +1.8 & $1 / 3$ & 342 & 18 & +178 & $1 / 3$ & 378 & 35 & +83 & $1 / 3$ & -36 & 16 & +96 & $1 / 3$ \\
\hline FRHes & 1997-2007 & 6.8 & 0.7 & +2.3 & $1 / 11$ & 335 & 55 & +99 & $1 / 11$ & 361 & 30 & +62 & $1 / 11$ & -26 & 37 & +37 & $2 / 11$ \\
\hline BEVie & 1997-2007 & 4.9 & 0.6 & +2.8 & $1 / 11$ & 484 & 31 & +115 & $1 / 11$ & 356 & 30 & +37 & $3 / 11$ & 128 & 46 & +79 & $2 / 11$ \\
\hline DETha & 1997-2007 & 5.1 & 1.1 & +2.6 & $1 / 11$ & 581 & 69 & +130 & $1 / 11$ & 392 & 50 & +93 & $1 / 11$ & 189 & 29 & +37 & $2 / 11$ \\
\hline FIHyy & 1997-2007 & -0.8 & 1 & +0.5 & $3 / 11$ & 202 & 26 & +40 & $1 / 11$ & 158 & 25 & +29 & $3 / 11$ & 44 & 27 & +12 & $4 / 11$ \\
\hline
\end{tabular}

$\Delta T$, spring (January-May) 2007 anomaly of mean air temperature compared to the 1997-2006 mean ( $\left.{ }^{\circ} \mathrm{C}\right) . \Delta \mathrm{GPP}, \Delta \mathrm{TER}, \Delta \mathrm{NEP}, \mathrm{spring}$ January-May) 2007 anomaly of GPP, TER and NEP sums compared with the 1997-2006 mean (gC m ${ }^{-2} / 5$ months). Mean and standard deviation (SD) over the 1997-2006 period are reported for comparison. Rank 07 reports the rank of year 2007 temperature or flux anomaly over the period of interest.

* Reported means, SD and anomalies are relative to the 2001-2006 period.

$\dagger$ Reported means, SD and anomalies are relative to the 2005-2006 period.

GPP, Gross primary productivity; NEP, net ecosystem productivity; TER, total ecosystem respiration.

relative flux anomaly caused by the $i$ th driver $\left(R A_{\Phi i}\right)$ was computed as the ratio of the modelled springtime $\Phi$ flux sum (DoY 1-151) on year y under full drivers variability to the modelled springtime $\Phi$ flux sum on year $y$ under partially forced simulation. Forced simulations were obtained by setting for each day of year the $i$ th driver of interest to its mean value on that day of year for the 1997-2006 period (Table 4), while other factors varied freely. The spring annual relative anomaly (RA) is therefore written as

$$
R A_{\Phi, i}(y)=\frac{\sum_{d=1}^{151} f_{\mathrm{ref}}(d, y)}{\sum_{d=1}^{151} g_{i}(d, y)},
$$

where $f_{\text {ref }}$ represents the flux simulated under full drivers variabilities and $g_{i}$ is the flux simulated under forcing of the $i$ th driver, while the other drivers vary freely. For instance, $R A_{\Phi, i}(y)=1.15$ indicates a $15 \%$ increase of flux $\Phi$ spring sum on year $y$ due to the deviation of factor $i$ from its mean pattern.

\section{Results}

The first part of this section is dedicated to flux data analysis. We characterise the anomalous 2007 spring (January-May) in terms of temperature and flux anomalies before illustrating the dependence of spring C fluxes on simple phenological indices. The second part of this section is based on the simulation analysis. After model validation, we analyse patterns of climatic and biological drivers for springtime $\mathrm{C}$ fluxes across sites and finally quantify the role of the drivers on spring 2007 fluxes.

\section{Flux data analysis}

Springtime temperature and fluxes: the 2007 exception. Springtime temperatures of the year 2007 were higher than the mean pre-2007 values at all sites (from +0.5 to $+2.8 \mathrm{~K}$, Table 5), and were highest ranked in the decade for all but the FIHyy site. Three 20-day warm spells (5 K above the decadal mean) were consistently observed across sites (DoY 1-20, 50-70 and 90-110) during spring 2007 (Fig. 2). At the boreal FIHyy site, the first spell (DoY 1-20) was later followed by a second warm period (DoY 60-90).

The 2007 springtime GPP sums were the highest recorded for all but the Mediterranean FRPue site (Table 5), as a consequence of early GPP onset (temperate deciduous FRHes, FRFon and boreal FIHyy sites) or of high GPP values compared with the decadal mean (temperate coniferous BEVie and DETha sites) (Fig. 2).

The 2007 TER springtime sums were the highest recorded for three sites (FRFon, FRHes and DETha), and higher than the mean for the other sites (Table 5). Assimilation fluxes were more enhanced than respiratory fluxes, which resulted in the spring 2007 NEP sums being the highest observed over the study period for the FRFon site while above the mean for the other sites (Table 5).

Simple phenological indices correlate with springtime fluxes. The relationship between the onset of the CUP and springtime NEP sum is presented in Fig. 3. Contrary to deciduous sites (FRFon and FRHes), all evergreen sites were springtime net $\mathrm{C}$ sinks throughout the study period. Over all sites, a decrease of the springtime net $\mathrm{C}$ balance with a late-starting CUP was noted. The reactivity (i.e. the slope) of springtime NEP to delayed 

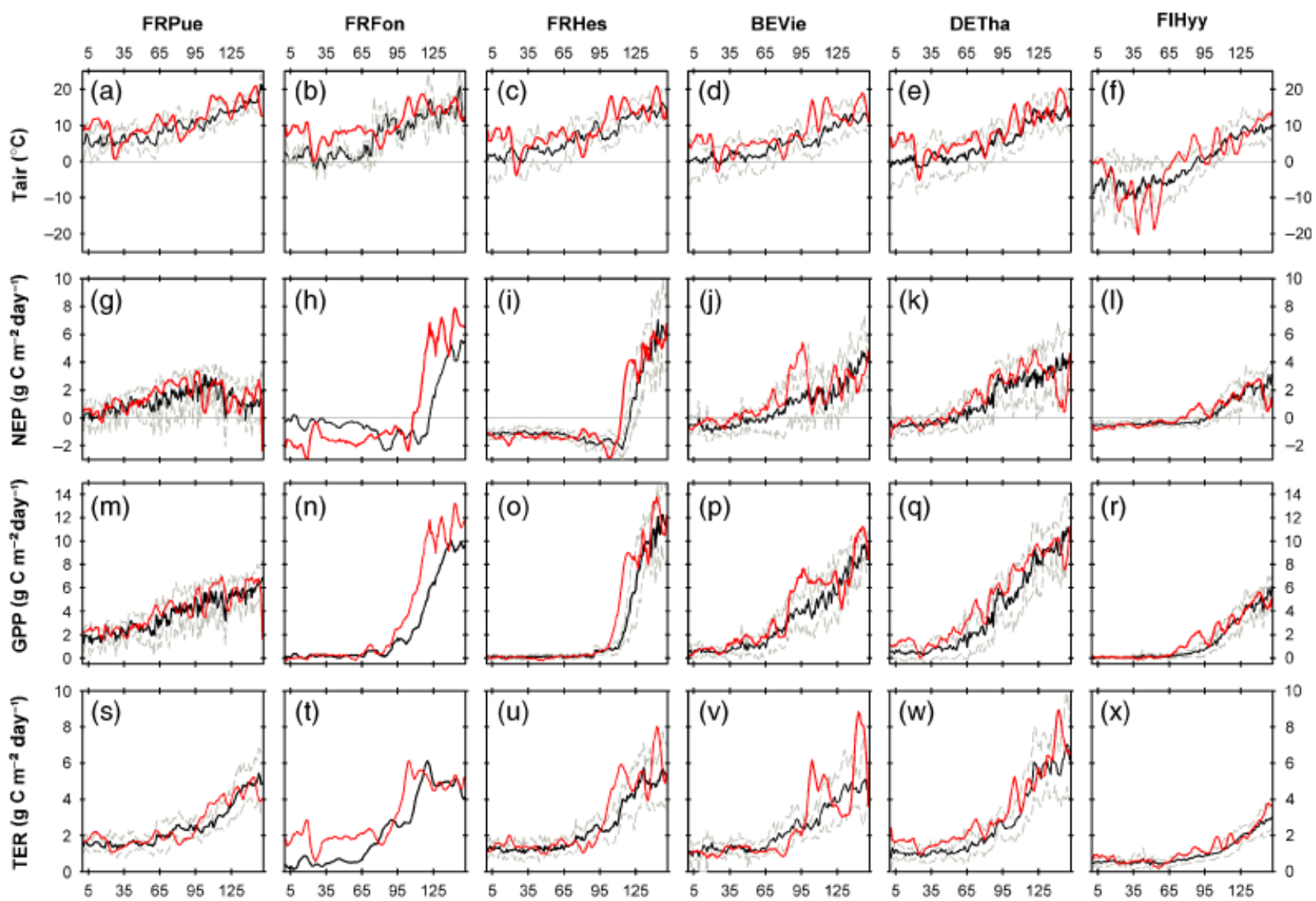

Fig. 2 Springtime dynamics of air temperature, gross primary productivity (GPP), total ecosystem respiration (TER) and net ecosystem productivity (NEP) for 6 European forests. Each subgraph is a time series (DoY 1-151), where black (grey) lines denote the mean ( \pm SD) 1997-2006 pattern. Red lines represent 5 days running means for year 2007.

CUP onset was strikingly different between though consistent within functional types, with a mean -7.0 (range -7.5 to -6.6 ) gC decreased sink for each day of later starting CUP in deciduous forests, while coniferous forests showed a mean $-1.3(-1.5$ to -1.1$)$

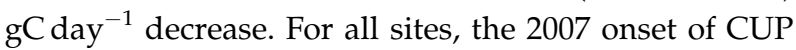
was advanced compared with the mean pre-2007 onset, and in some cases was the earliest recorded (Fig. 3).

The springtime GPP sum was significantly correlated with the sum of positive air temperature for all evergreen sites but FRPue (Fig. 4a). For the deciduous FRHes site, the GPP starting date was a better descriptor of the springtime GPP sum variability than the temperature sum (Fig. 4). No significant relationship could be established with either index for the deciduous FRFon site (three site-years), which aligned on the FRHes site relationship (Fig. 4b). Relationships drawn for both deciduous and evergreen forests clearly illustrated the exceptional nature of the 2007 spring with the highest temperature sums (earliest GPP starting date) associated with the highest measured GPP in evergreen (deciduous) sites.
For three out of six sites, the best predictor of springtime TER was springtime GPP (Table 6). For the boreal FIHyy and temperate FRFon sites, the sum of positive air temperatures was the best predictor of springtime TER, while no significant relationship could be established with either predictor for the temperate coniferous BEVie site.

\section{Simulation analysis}

Model validation. Model simulations of the springtime dynamics of diurnal NEP (NEPd) proved accurate across the considered latitudinal range, with squared correlation coefficients values between measured and modelled NEPd time series in the 0.59-0.98 range (mean 0.86, Fig. 5). For sites characterized by a strong seasonality of NEPd, such as the temperate deciduous FRHes or boreal coniferous FIHyy sites, the model correctly reproduced the mean respiratory winter values, and fairly timed the subsequent sharp rise of NEPd. This feature was expected for the deciduous FRHes site where budburst was forced ('Modelling of 
the $\mathrm{C}$ balance'). For the temperate coniferous DETha site, the alternation between active/inhibited photosynthesis periods appearing through the rugged NEPd patterns was correctly modelled. Lower $r^{2}$ values

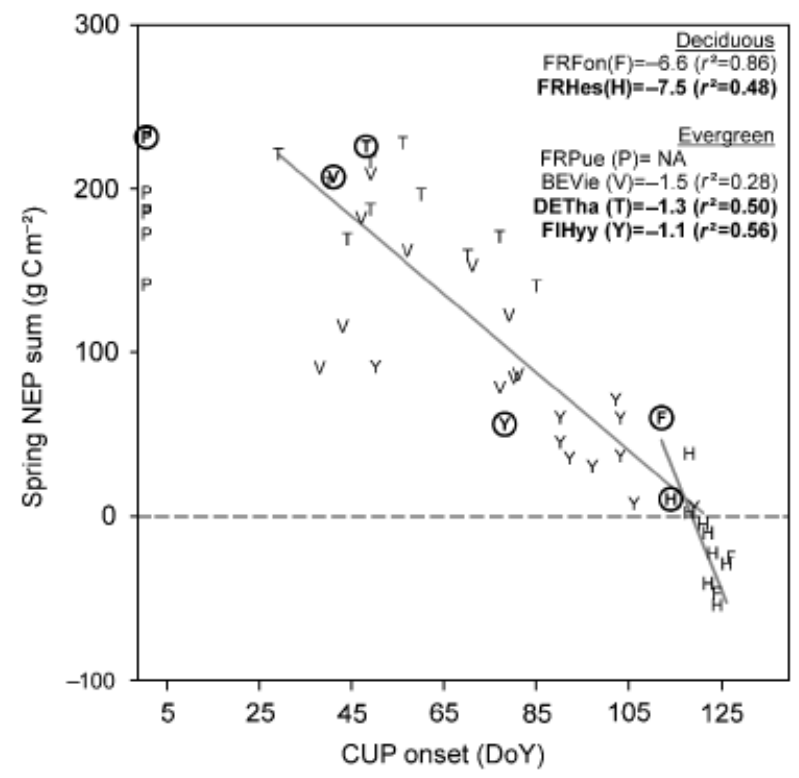

Fig. 3 Springtime net ecosystem productivity (NEP) sum as a function of the date of carbon uptake period (CUP) onset. Letters denote particular sites: P, FRPue; F, FRFon; H, FRHes; V, BEVie; T, DETha; Y, FIHyy. Year 2007 fluxes are circled. Insets report the site slopes of the relationship (significance at the 5\% threshold denoted by bold characters, NA, not assessed). No relationship could be established for FRPue, as this site was a consistent $C$ sink throughout the January-May period (no CUP onset could be detected). Overall relationships (grey lines): Evergreens: $\mathrm{NEP}=-2.38 \times \mathrm{CUP}_{\text {onset }}+290\left(R^{2}=0.66, P<10^{-4}\right)$; Deciduous: $\mathrm{NEP}=-7.07 \times \mathrm{CUP}_{\text {onset }}+838\left(R^{2}=0.58, P<0.001\right)$.

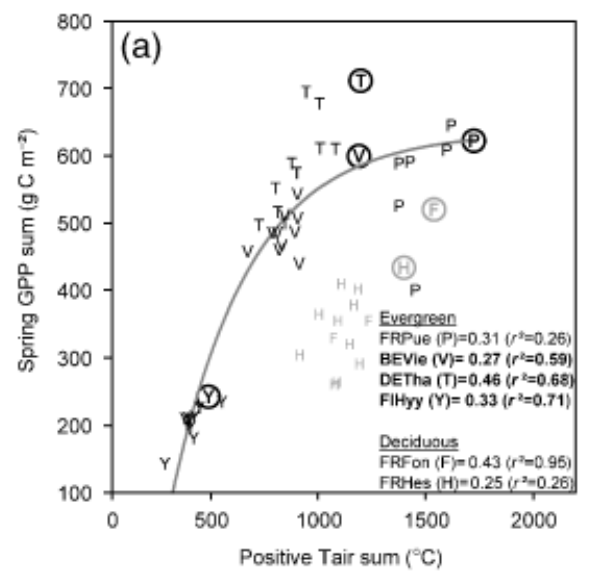

were obtained for the Mediterranean FRPue forest, where day-to-day variations of NEPd (e.g. reversals from net sinks to sources caused by variations of incoming radiation) were well simulated, but the model could not capture the complete range of NEPd, particularly for years 2001 and 2003. Such underestimations of NEPd maxima appeared sporadically at other sites. The accuracy of simulations for the Mediterranean FRPue site benefited from forcing LAI reduction following the Lymantria attack on the currentyear leaf cohort in June 2005 (Allard et al., 2008), though the low measurements range of 2006 caused a low $R^{2}$ value $\left(R^{2}=0.59\right)$. The new leaf cohort emitted in 2007 allowed for a LAI increase and accurate representation of higher NEPd.

We noticed a fair simulation of the NEPd and GPP spring sums over all sites, with squared correlation coefficients values ranging from 0.55 to 0.81 for NEPd,

Table 6 Pearson's correlation coefficients relating annual springtime variables to annual TER springtime sums

\begin{tabular}{lll}
\hline & \multicolumn{2}{l}{ Spring variable } \\
\cline { 2 - 3 } & GPP sum & $T_{\text {air }}>0$ sum \\
\hline FRPue & $+0.93^{*}$ & +0.57 \\
FRFon & +0.94 & +0.99 \\
FRHes & $+0.86^{*}$ & +0.49 \\
BEVie & +0.19 & +0.41 \\
DETha & $+0.95^{*}$ & $+0.69^{*}$ \\
FIHyy & +0.52 & $+0.71^{*}$ \\
\hline
\end{tabular}

*Significance at the $5 \%$ threshold.

GPP, Gross primary productivity; $T_{\text {air }}$ air temperature; TER, total ecosystem respiration.

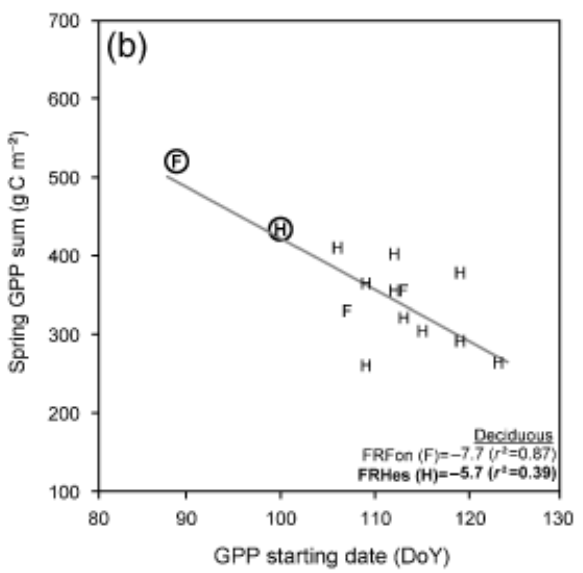

Fig. 4 Relating phenological indices to gross primary productivity (GPP) sums in deciduous and evergreen sites. Year 2007 fluxes are circled. Each site is represented by its initial letter, as in Fig. 3. (a) Evergreen sites, with deciduous sites reported in grey; (b) Deciduous sites. Insets report the site slopes of the relationship (significance at the $5 \%$ threshold denoted by bold characters). Overall relationships (grey lines): Evergreens: $\mathrm{GPP}=635 \times(1-\exp (-0.00272 \times(\Sigma \mathrm{T}-259)))\left(R^{2}=0.85, P<10^{-4}\right)$; Deciduous: $\mathrm{GPP}=-6.55 \times \mathrm{GPP}_{\text {start }}+1076$ $\left(R^{2}=0.60, P<0.01\right)$. 


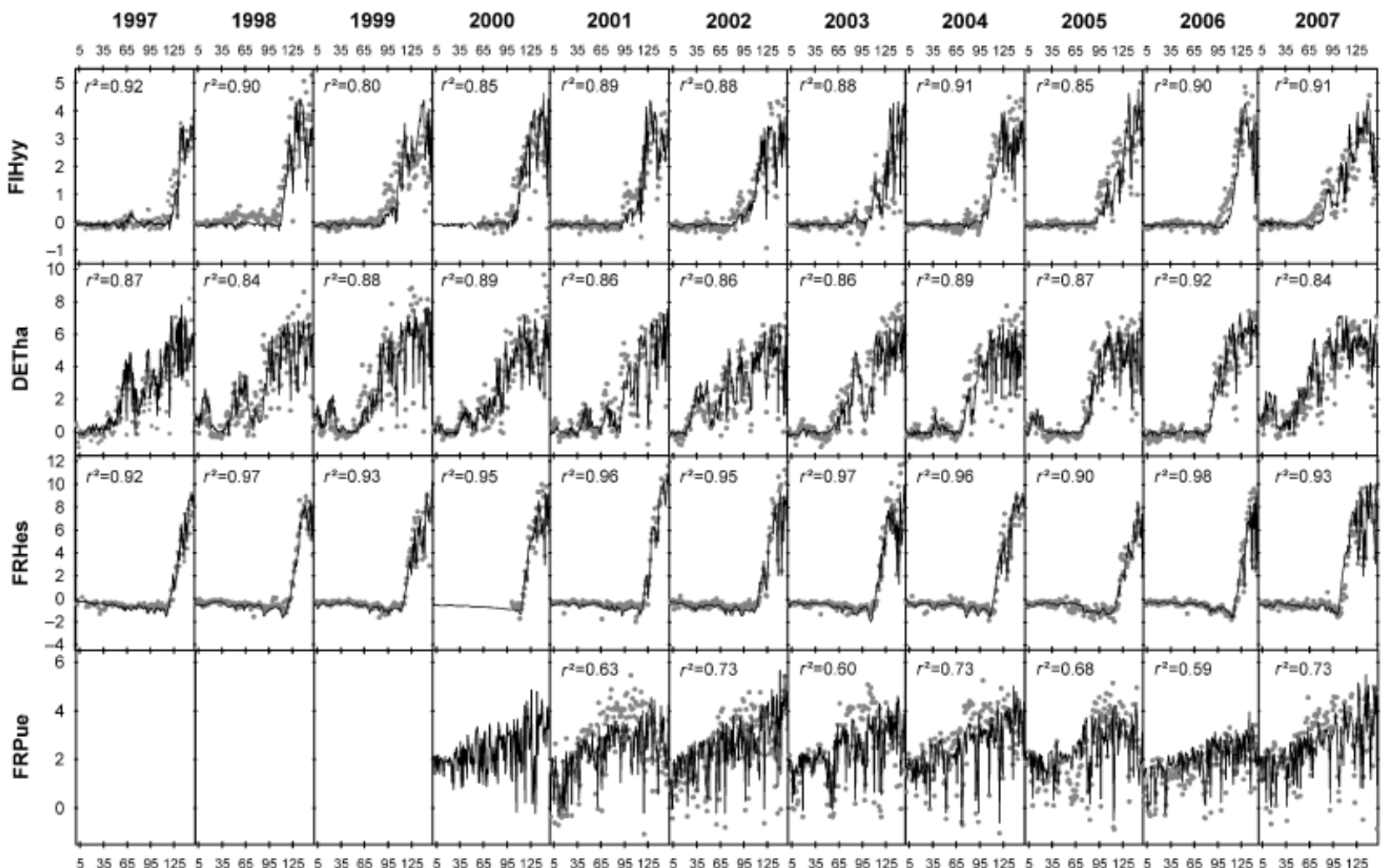

Fig. 5 Comparison of modelled and measured diurnal net ecosystem productivity (NEP) time series. Each subgraph is a time series (DoY 1-151) of measured (dots) and modelled (lines) diurnal NEP (NEPd, $\mathrm{gC} \mathrm{m}^{-2} \mathrm{day}^{-1}$ ). All correlation coefficients, reported in their squared form, were significant at the $5 \%$ threshold. $X$-axis represents the day of year.

and from 0.64 to 0.90 for GPP. RMSE values ranged from 15 to $34 \mathrm{gC} \mathrm{m}^{-2}$ for NEPd and from 12 to $58 \mathrm{gC} \mathrm{m}^{-2}$ for GPP (Fig. 6). CASTANEA and eddy covariance estimates of spring GPP were overall within $8 \%$ of each other.

Influence of climatic and biological drivers on $C$ fluxes. We report in Fig. 7 the calculated springtime patterns of climatic and biological driver influences on GPP, TER and NEP fluxes. Squared multiple correlation coefficients $\left(R^{2}\right)$ in the $0.6-1.0$ range (most frequently between 0.8 and 1.0) for all sites and fluxes validate our reconstruction of the flux simulated under full drivers variability from partially forced simulations by the MLR method [Eqn (1)]. The weak departure of $R^{2}$ from 1.0 further proved that interactions terms and unconsidered potential drivers played a minor role in the modulation of simulated fluxes.

Owing to the differences in functional types (deciduous vs. evergreen) and climatic conditions range (Mediterranean to boreal), the spring drivers' patterns of influence on a given flux appeared strikingly different between sites.

Influence of climatic and biological drivers on GPP. For both temperate and boreal coniferous sites (DETha and FI-
Hyy), throughout the January-May period, temperature exacts a strong influence on GPP modulations, either through direct effects of air temperature $\left(T_{\text {eco }}\right)$ on photosynthesis enzyme kinetics or through the photosynthesis acclimation factor (biological integrator of the thermal influence, AccP; Fig. 7a and d). The biological AccP driver dominated GPP control during most of the spring. The climatic $T_{\text {eco }}$ driver had its heaviest influence on GPP control towards the end of the springtime period when above-freezing temperatures induced a relief of the thermal acclimation constraint (AccP), but air temperatures were still low enough to limit photosynthetic enzyme kinetics. Another period during which the climatic $T_{\text {eco }}$ driver exerted its influence on GPP at the boreal FIHyy forest occurred when deepfreezing periods caused the AccP factor to maintain its minimal value from year to year (DoY 35-65; Fig. 7d).

For both temperate deciduous (FRHes) and Mediterranean evergreen (FRPue) sites, the influence of temperature drivers on GPP modulation was less important than for coniferous sites. For the evergreen FRPue site, $T_{\text {eco }}$ influence on GPP diminished across the JanuaryMay period (Fig. $7 \mathrm{~g}$ ) as rising temperatures became less limiting for photosynthesis. For the deciduous FRHes forest, the main influence of $T_{\text {eсо }}$ on GPP modulations 

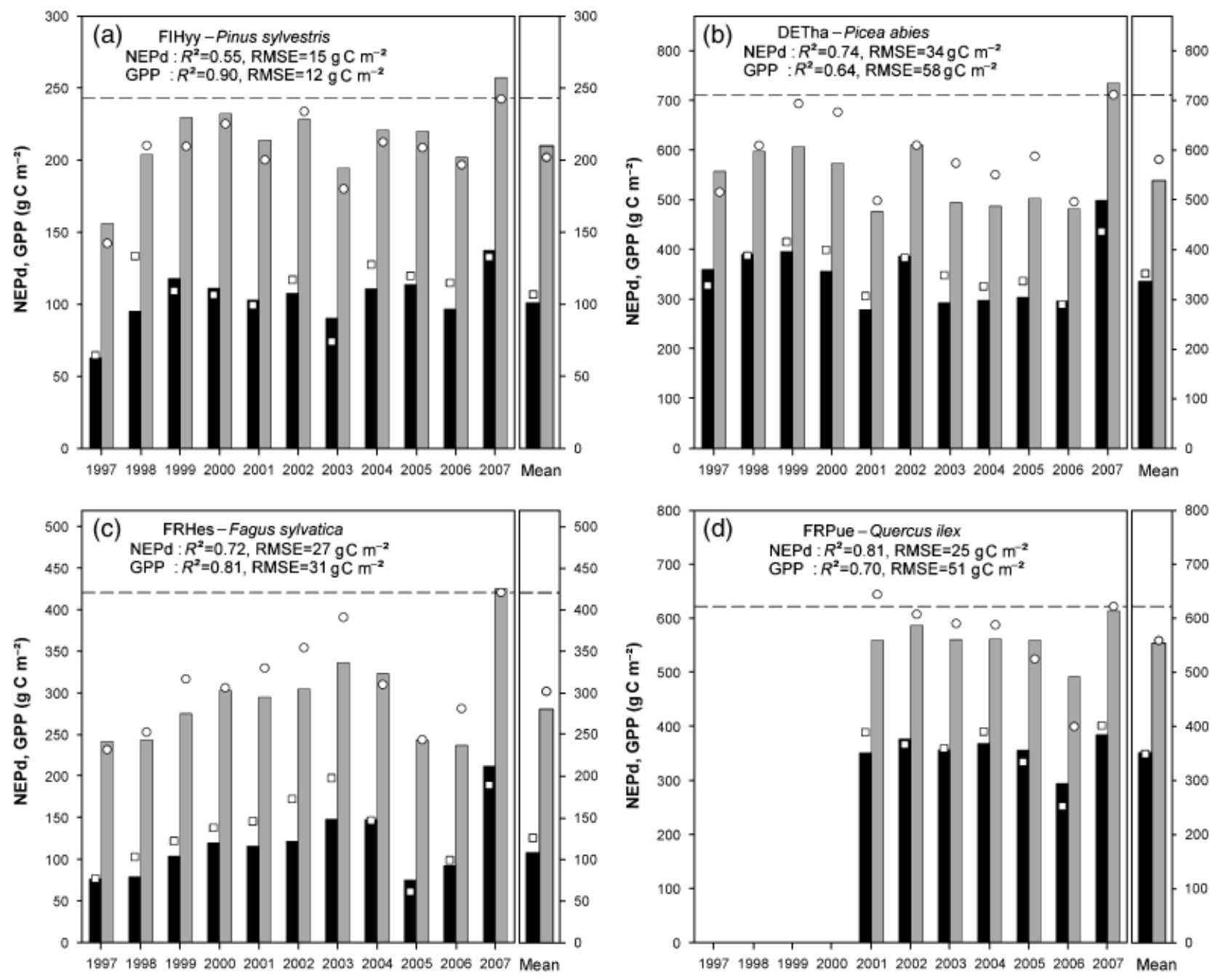

Fig. 6 Comparison of modelled and measured spring flux sums. Black bars, simulated diurnal net ecosystem productivity (NEPd); squares, measured NEPd; grey bars, simulated gross primary productivity (GPP); circles, eddy-covariance separated GPP. Dashed lines mark the 2007 spring GPP values. For each site, both the 1997-2007 springtime series and mean values before 2007 are reported. Note that for the FRHes site, eddy-covariance separated GPP before budburst were set to zero. All squared correlation coefficients between measured and modelled values were significant at the 5\% threshold. X-axis represents years from 1997.

occurred during the transition (DoY 120-140) from foliar biomass (CDyn)-driven GPP to incoming radiation (Rg)-driven GPP (Fig. 7j). During this period, $T_{\text {eco }}$ affected GPP by both modulation of photosynthesis kinetics and leaf mass per area development.

The incoming radiation $(\mathrm{Rg})$ climatic driver mainly modulated GPP after the relief of other constraints: either thermal in northern coniferous forests, or structural in deciduous forests (after canopy development). As these constraints were of less importance for the Mediterranean site, $\mathrm{Rg}$ appeared there as the main GPP driver throughout spring (Fig. 7g).

Structural variations of the canopy, as assessed from the CDyn factor, strongly influenced GPP in the deciduous FRHes site where GPP modulation was mainly dependent on leaf mass build-up in a 1-month period spanning DoY 100-130 (Fig. 7j). A more diffuse influence of CDyn on GPP modulation was observed for the evergreen broadleaf site (FRPue, Fig. 7g), where the 2005 caterpillar attack caused a 15\% LAI decrease from the original $2.9 \mathrm{~m}^{2} \mathrm{~m}^{-2}$ maximum seasonal value (Table 1), generating a strong interannual variability of LAI. In coniferous sites, the impact of LAI variations, either due to interannual variations of needle flush or thinning, was discernable (Fig. 7a and d) but to a lesser extent than noticed for the FRPue site.

Influence of climatic and biological drivers on TER. Over all sites, TER modulations were first driven by $T_{\text {eco }}$ (Fig. 7). CDyn could also modulate TER following a sharp structural change in canopy structure (leaf mass devel- 

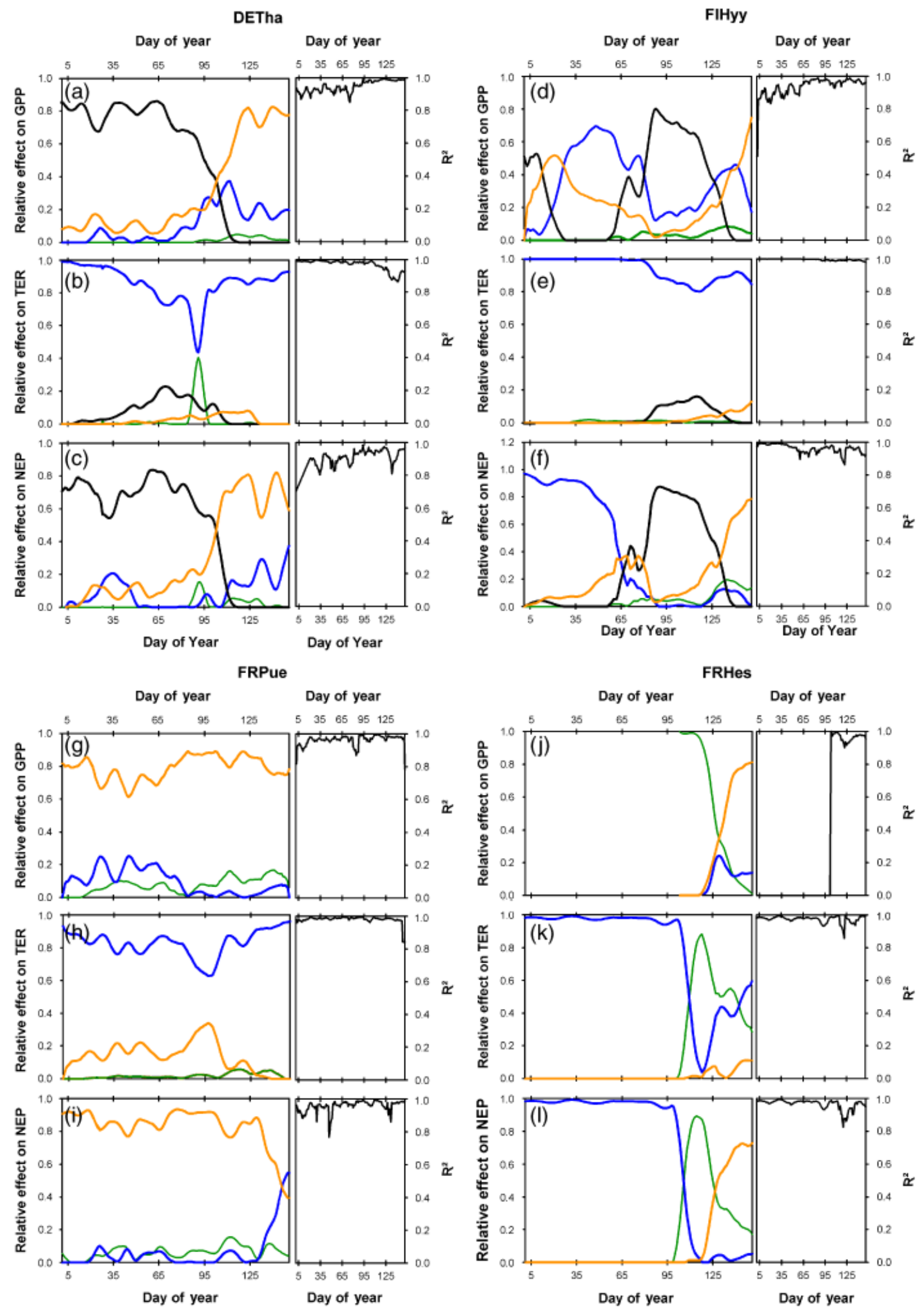

(C) 2009 Blackwell Publishing Ltd Journal compilation No claim to original US government works, Global Change Biology, doi: 10.1111/j.1365-2486.2008.01835.x 

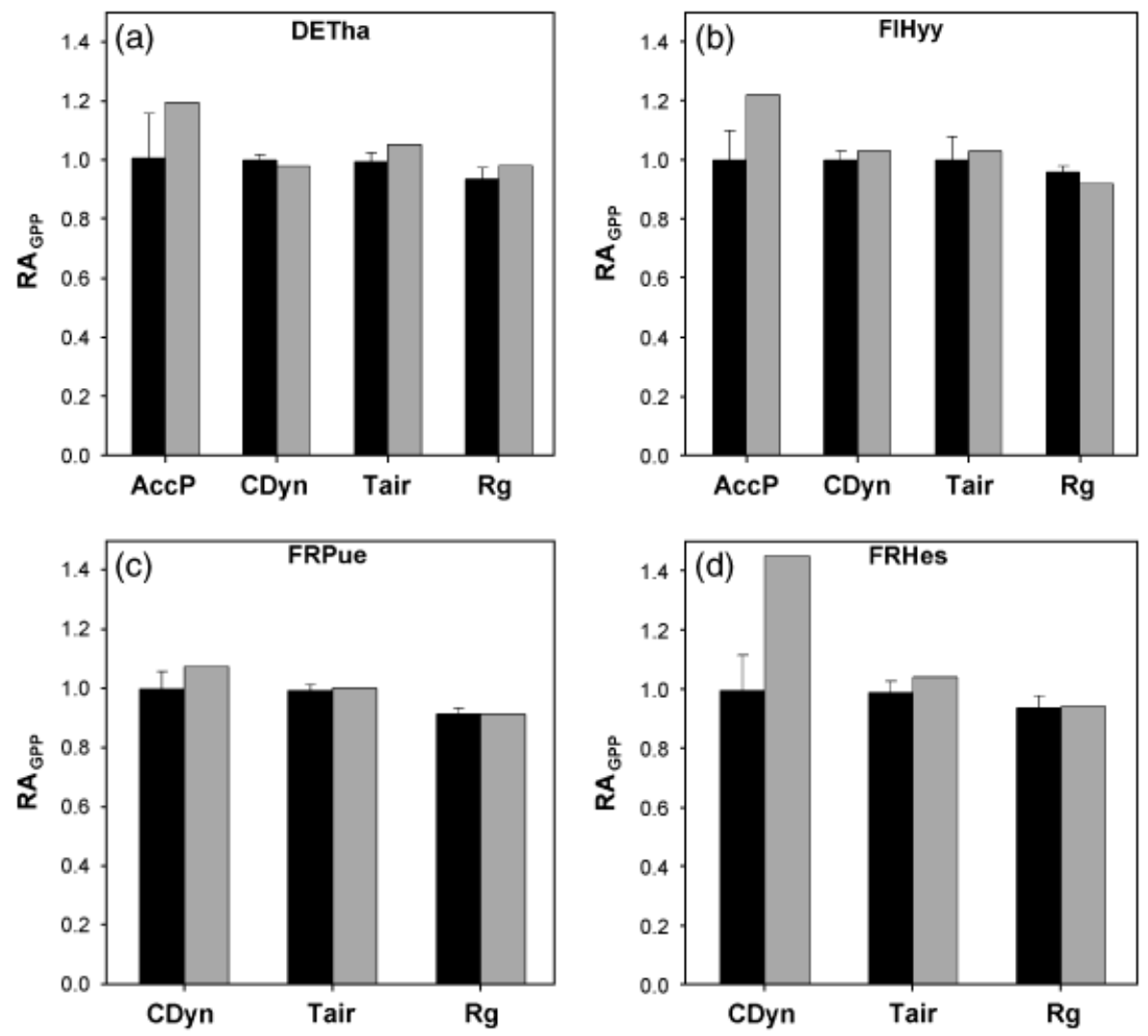

Fig. 8 Influences of climatic and biological drivers on spring 2007 gross primary productivity (GPP) relative anomalies (RA). Black bars (whiskers) represent the pre-2007 mean (maximum) RA attributable to each biological and climatic factor. Grey bars represent the 2007 RA. AccP, photosynthesis thermal acclimation factor; CDyn, canopy dynamics; $T_{\text {air, }}$ air temperature; $\mathrm{Rg}$, global radiation. $T_{\text {air }}$ is mentioned instead of $T_{\text {eco }}$ as no influence of soil temperature on GPP is accounted for in the model. The concavity of the assimilationradiation relationship in the model caused the mean pre-2007 enhancement factor associated to $\operatorname{Rg}$ to be less than one.

opment in FRHes, Fig. 7k, thinning on DoY 90 in DETha, Fig. 7b). Worthy of note were the influences of the $\mathrm{Rg}$ and AccP factors on the TER modulation, at all sites, as these drivers were not directly implicated in the model TER calculations. Their influences reflected the functional link of TER with GPP. For instance, $\mathrm{Rg}$ influenced TER by the end of May in FRHes (Fig. 7k), and throughout springtime in FRPue (Fig. 7h). Similarly, Rg and AccP both affected TER modulation throughout the season in DETha (Fig. 7b), and from the rise of GPP fluxes in FIHyy (Fig. 7e).

Influence of climatic and biological drivers on NEP. Relative effects of climatic and biological drivers on NEP resulted from the combination of relative effects on GPP and TER. For both FRHes and FIHyy sites, which are characterized by strong NEP seasonal variations, the first part of the NEP driving pattern was dominated by $T_{\text {eco }}$ (resembling that of TER) while the second part was reminiscent of the GPP pattern (Fig. $7 f$ and 1). For DETha and FRPue, which are characterized by significant GPP fluxes throughout the January-May period, the NEP driving pattern resembled that of GPP (Fig. 7c and i).

Climatic and biological impacts on 2007 fluxes. In Figs 8 and 9 we present the GPP and TER annual RAs computed from simulated fluxes [Eqn (3)] for each site. These graphs quantify the influence of each driver on the exceptional spring 2007 flux values.

Model simulations revealed exceptional 2007 GPP

Fig. 7 Spring (January-May) patterns of elementary flux drivers, derived from simulations analysis. Left subgraphs represent the proportion of interannual variability explained on the given DoY by the considered factor [Eqn (2)]. Black, photosynthesis thermal acclimation factor (AccP); green, foliar biomass (CDyn); blue,ecosystem temperature $\left(T_{\text {eco }}\right)$; orange,incident shortwave radiation (Rg). Right subgraph, squared multiple correlation coefficient of the multiple regression relating full variability fluxes to partially forced fluxes [Eqn (1)]. 

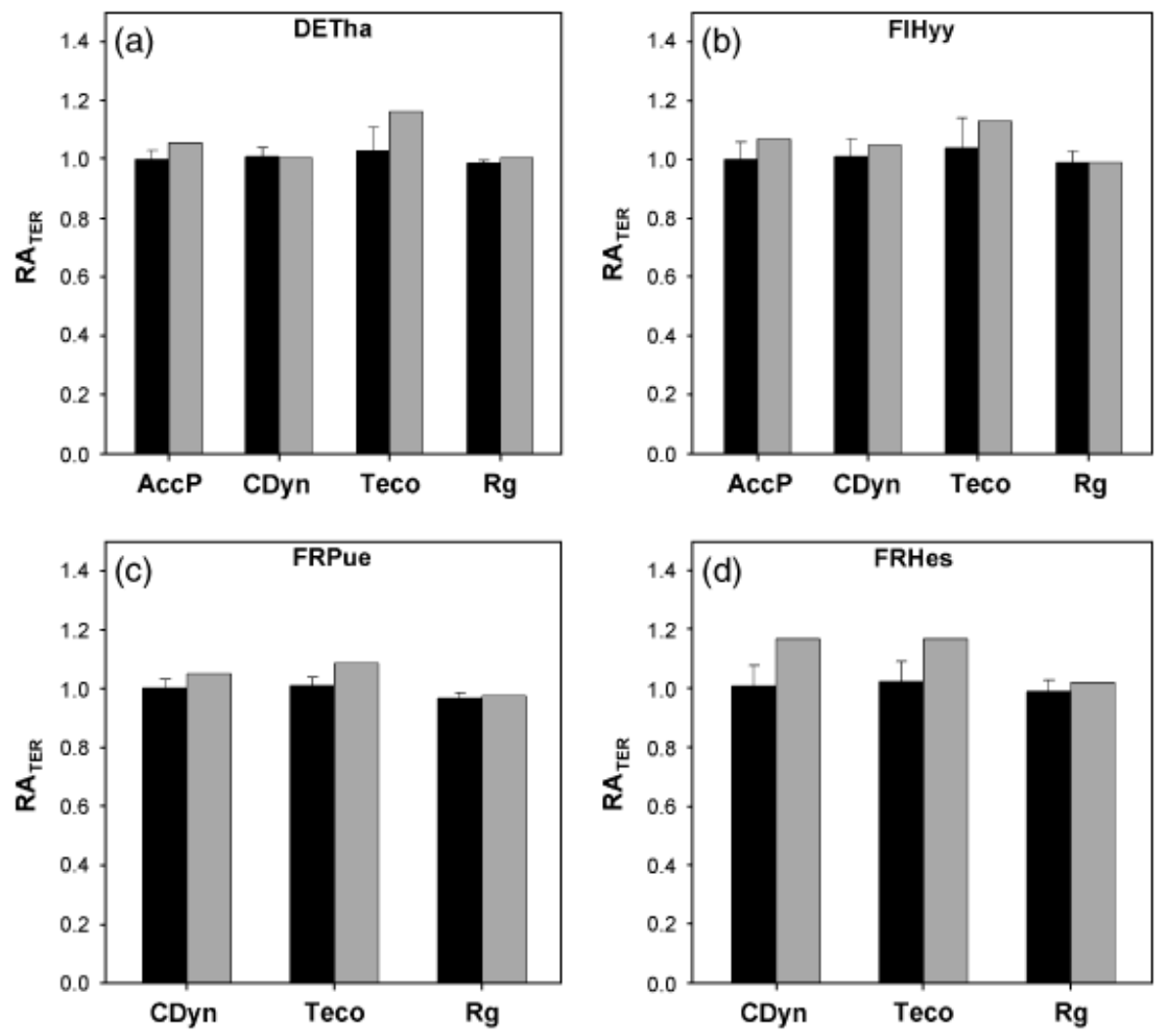

Fig. 9 Influences of climatic and biological drivers on spring 2007 total ecosystem respiration (TER) relative anomalies (RA). Black bars (whiskers) represent the pre-2007 mean (maximum) RA attributable to each biological and climatic factor. Grey bars represent the 2007 RA. AccP, photosynthesis thermal acclimation factor; CDyn, canopy dynamics; $T_{\mathrm{eco}}$, ecosystem (air and soil) temperature; $\mathrm{Rg}$, global radiation. The convexity of the temperature-respiration relationship in the model caused the mean pre-2007 enhancement factor associated to $T_{\text {eco }}$ to be $>1$.

enhancements for all sites, with a 2007 RA greater than the maximum pre-2007 value for at least one driver (Fig. 8). These results were consistent with flux measurements: for the three sites for which the model predicted exceptional enhancements in spring 2007 GPP (FRHes, DETha and FIHyy), the measured spring 2007 values were the highest recorded (Table 5, Fig. 6). For the FRPue site, the model predicted the highest spring GPP sum to occur in 2007, while the highest measured spring GPP was observed in 2001 (Fig. 6).

For both coniferous sites, the exceptional GPP of spring 2007 was, according to the model, caused mainly by the early relief of the photosynthesis acclimation constraint (AccP), resulting in a $+20 \%$ GPP increase in model simulations $\left(+100 \mathrm{gC} \mathrm{m}^{-2}\right.$ for DETha, $+40 \mathrm{gC} \mathrm{m}^{-2}$ for FIHyy; Fig. 8a and b), relative to simulations that compelled AccP to follow its mean pattern. The GPP anomaly during spring 2007 in the deciduous FRHes site was mainly related to the CDyn factor. The 15-day advanced canopy setup in spring 2007 caused a $+42 \%$ $\left(+125 \mathrm{gC} \mathrm{m}^{-2}\right)$ increase in simulated GPP (Fig. $8 \mathrm{~d}$ ).

At all sites, the climatic $T_{\text {eco }}$ factor participated in the increase of spring GPP sum, as a positive anomaly from

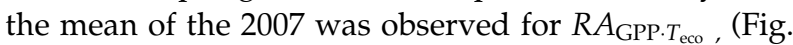
8). However, the pure climatic $T_{\text {eco }}$ effect was of limited influence and did not fully explain the exceptional 2007 GPP.

The analysis of TER enhancement factors revealed exceptional increases for all sites, with a 2007 RA greater than the maximum pre-2007 value for at least one driver (Fig. 9). For all sites, elevated 2007 temperatures $\left(T_{\mathrm{eco}}\right)$ were the principal cause of the spring 2007 TER enhancement. This effect was associated with a promotion of 2007 TER by CDyn in the FRHes site (Fig. 9d).

\section{Discussion}

\section{SVAT models as tools to disentangle the influences of climatic and biological drivers on C fluxes}

For two decades, process-based SVAT models have been considered as fundamental tools for the study of the forest component of biogeochemical cycles (e.g. 
Aber \& Federer, 1992; Sala \& Tenhunen, 1996; De Pury \& Farquhar, 1997). SVAT models are usually used as tools for retrospectively and/or prospectively predicting the response of forest ecosystems to climate change and/or anthropogenic disturbances, in terms of C fluxes and stocks (Thornton et al., 2002; Churkina et al., 2003; Schimel et al., 2005, but see Davi et al., 2006, for a CASTANEA application). Recent modelling papers discussing the summer 2003 European heat wave/drought stress also underlined the importance of SVAT models for the study of extreme events, either in terms of spatialization (Ciais et al., 2005; Reichstein et al., 2007; Vetter et al., 2008) or for deriving ecosystem functional indices (Granier et al., 2007). In this study, we used the CASTANEA model in a different way, as a tool for quantifying the influences of climatic and biological drivers on the interannual variability of $C$ fluxes: (i) at a daily timescale $\left[e_{i}\right.$ indexes; Eqn (2), Fig. 7] and (ii) at seasonal time scale [RA indexes; Eqn (3), Figs 8 and 9].

CASTANEA accurately represented net $C$ fluxes at daily (Fig. 5) to seasonal (Fig. 6) time scales, and in previous studies proved accurate at simulating individual (organ-scale) processes (Davi et al., 2005), which gave us confidence in the model structure. CASTANEA contains more than 150 parameters, including speciesspecific parameters (compiled from the literature, see Dufrêne et al., 2005 for a thorough review) and standspecific parameters (collected in situ, Table 2). The use of a given set of parameters, which carry their own uncertainties, might introduce compensating errors in the model simulations (Medlyn et al., 2005), which are not detectable through validation with net $C$ fluxes and may bias the quantification of driver influences on $C$ fluxes. A sensitivity analysis was conducted in order to test for the robustness of $e_{i}$ and $R A$ indexes to parameters uncertainties. The sensitivity analysis revealed that both $e_{i}$ and $R A$ indexes departed $<5 \%$ and $1 \%$, respectively, from their original values when the five most sensitive parameters associated with each climatic and biological driver were varied by $\pm 10 \%$ (not shown). The robustness of functional drivers indexes $\left(e_{i}\right.$ and $R A$ ) proceeds from the very definition of the indexes, as Eqn (2) uses centred-reduced fluxes as variables, and Eqn (3) is the ratio of two fluxes, so that both indexes are marginally affected by mean-centred deviations of simulated fluxes caused by parameters uncertainties.

\section{Resolving $C$ fluxes determinism through simulation deconvolution}

The analysis of measured spring fluxes through a correlative approach showed phenological temperature-related indexes (date of GPP onset and sum of positive temperatures, Fig. 4) to be good descriptors of the interannual variability of springtime GPP sums. Contrary to such indexes, established at an annual time scale, CASTANEA simulations could be used to disentangle the influences of climatic and biological drivers on $\mathrm{C}$ fluxes at both daily and integrated (annual) time scales. CASTANEA simulations of spring GPP were for three out of four sites better correlated with eddy covariance-separated GPP $\left(\mathrm{GPP}_{\mathrm{ec}}\right)$ sums than were phenological indexes $\left(R^{2}\right.$ values of simulated GPP and $\mathrm{GPP}_{\mathrm{ec}}$ were $-4 \%$ to $+49 \%$ higher than $R^{2}$ values of phenological indexes and $\mathrm{GPP}_{\mathrm{ec}}$ ). This further evidenced that spring GPP sums do not rely on a sole event (GPP onset) or driver (air temperatures), but on the integration of fine time scale influences of climatic and biological drivers.

An important result of the analysis of driver influences was the illustration of the functional link between GPP and TER fluxes. Experimental studies demonstrated that soil respiration (Tang et al., 2005; Sampson et al., 2007) as well as trunk respiration (Zha et al., 2004) were partially correlated with GPP, which provides photosynthates used for growth or maintenance of tree organs and rhizosphere (Högberg et al., 2001). At all study sites, the principal driver of simulated TER variability was temperature (Fig. 7). However, TER variability was also influenced by GPP drivers, which do not directly impact TER in the model calculations (i.e. radiation $\mathrm{Rg}$ and thermal acclimation factor AccP; Fig. 7). For most of the January-May period, no wood growth was simulated in CASTANEA for either species. In the model, wood growth is triggered after budburst in Fagus (April), within days following needle flush in conifers (May), and begins in April for Q. ilex, consistently with experimental results (Rambal et al., 2004; Zweifel et al., 2006; Granier et al., 2008). However, experimental studies showed that fine root growth continues throughout the winter in Pinus sylvestris (Konopka et al., 2005) and Q. ilex (Lopez et al., 2001). Accordingly, the dependency of simulated TER on GPP drivers was due to fine root growth, which could in the model represent up to $20 \%$ of late spring TER in coniferous sites (DETha and FIHyy), 15\% in the Mediterranean evergreen (FRPue) and 5\% in the deciduous site (FRHes).

The mechanisms of spring photosynthesis resumption in conifers are still subject to debate, as several authors (e.g. Schwarz et al., 1997; Jarvis \& Linder, 2000) hypothesise a decisive role of soil temperature, on the argument that spring transpiration recovery accompanying photosynthesis resumption requires soil water to be in liquid phase (i.e. soil thaw) in order to be absorbed by active (temperature-limited) roots. Suni et al. (2003a) demonstrated that for sites of moderate 
soil freezing, photosynthetic activity was detectable up to 1.5 months before soil thaw, as trees could probably partly rely on xylem water content to satisfy the very low evaporative demand (Sparks et al., 2001). In CASTANEA, the resumption of photosynthesis in coniferous forests is not dependent on soil temperature (the AccP factor relies on air temperature, see 'Modelling of the $\mathrm{C}$ balance'). On the other hand, the northernmost site scoped in this study (FIHyy) is not subject to winter soil freezing (Suni et al., 2003a, b). The CASTANEA model was not tested at higher-latitude (colder) sites than FIHyy, so we cannot conclude whether it is useful to implement in the model the influence of soil temperature on spring photosynthesis resumption for higher-latitude sites. If relevant, the integration of such a soil temperature effect might modify the indicative pattern of functional constraints presented in Fig. 7 for a boreal forest, based on the FIHyy example.

\section{Analogous responses of temperate coniferous and deciduous forests to spring temperature anomaly}

In a recent study addressing the question of differential responses of the $\mathrm{C}$ balance of boreal forests to spring warming, Welp et al. (2007) reported a higher anomaly of spring GPP (April-June in their study) in a boreal deciduous stand (Populus tremuloides, $+106 \mathrm{gC} \mathrm{m}^{-2}$ ) as compared with a boreal coniferous stand (Picea mariana, $+28 \mathrm{gC} \mathrm{m}^{-2}$ ), in response to a $+3{ }^{\circ} \mathrm{C}$ temperature increase (Table 2 in Welp et al., 2007). Concomitant increases in TER ( +54 and $+17 \mathrm{gC} \mathrm{m}^{-2}$, respectively) led to a higher enhancement of NEP in the deciduous stand compared with the coniferous stand. The authors suggested that their results might illustrate the differential responses of deciduous and coniferous species to future climate changes. Our study complemented these results, as we showed that a +2.3 to $+2.6 \mathrm{~K}$ temperature anomaly led to comparable anomalies in GPP $(+100$ $\left.130 \mathrm{gC} \mathrm{m}^{-2}\right)$, TER $\left(+60-90 \mathrm{gC} \mathrm{m}^{-2}\right)$ and NEP $\left(+40 \mathrm{gC} \mathrm{m}^{-2}\right)$ in two deciduous and coniferous forests located at temperate latitudes (FRHes and DETha, Table 5). Compared with the results of Welp and colleagues, our findings illustrate a modification of the relative sensitivities of coniferous and deciduous forests to spring warming from temperate to boreal latitudes. Our results further temper the conclusions about the supposedly higher contribution to the variability of $\mathrm{CO}_{2}$ atmospheric concentration from deciduous forests relative to coniferous forests, which arose from work published for boreal forests (Arain et al., 2002; Welp et al., 2007).
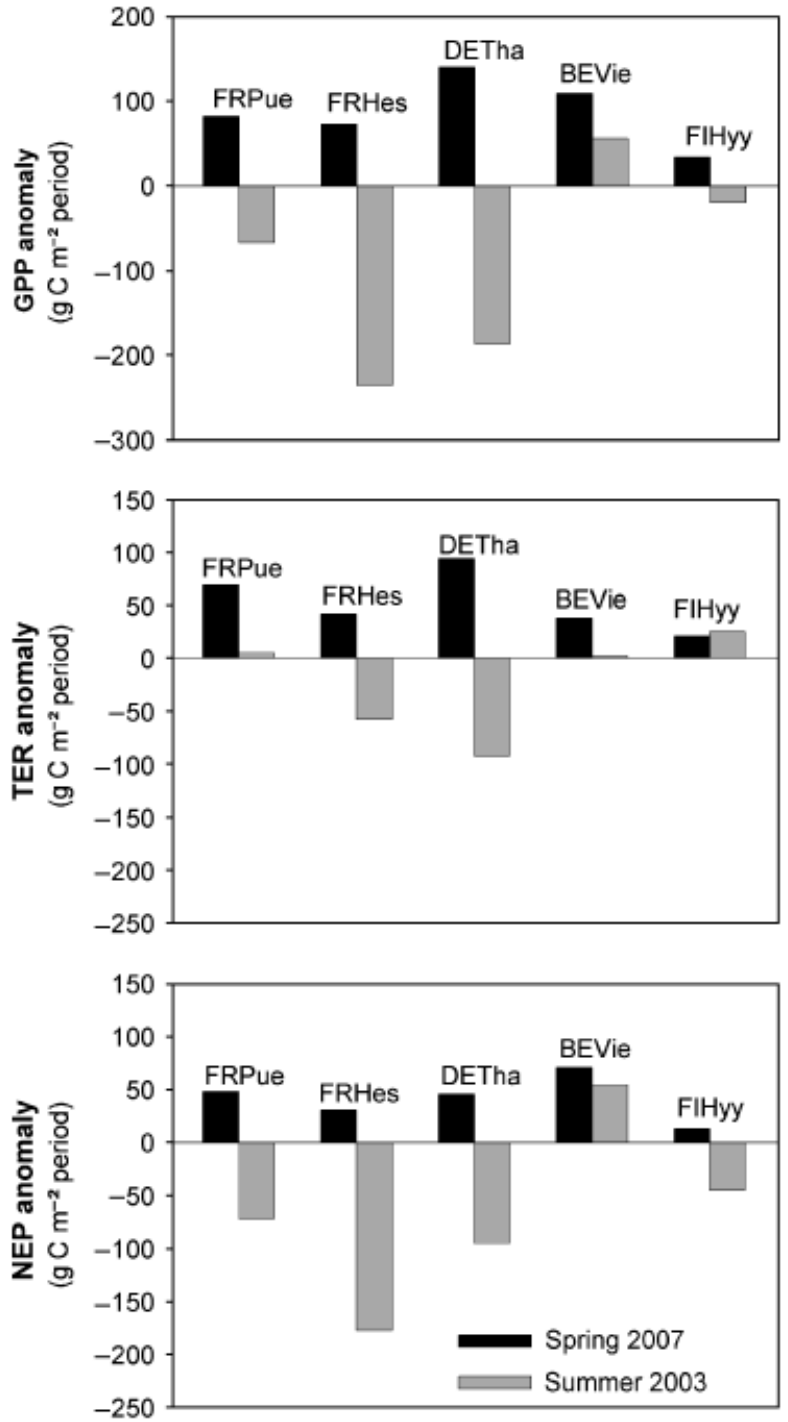

Fig. 10 Comparison of spring 2007 and summer 2003 fluxes anomalies. Anomalies are calculated in $\mathrm{gC} \mathrm{m}^{-2}$ over the period of integration (January-May for spring, July-September for summer) by comparison with the 2000-2007 and 2000-2006 means for spring and summer, respectively. No data were available in 2003 for the FRFon site, which does not appear on the graph.

\section{Will warm springs enhance annual NEP?}

The exceptional GPP and NEP of European forests during the spring of 2007 appear in line with a trend towards an earlier onset of $\mathrm{C}$ uptake, demonstrated back to the 1980s through flask sampling/atmospheric inversion (Randerson et al., 1999) and remote sensing of continental greenness (Myneni et al., 1997; Zhou et al., 2003). Climate models predict winter temperatures at the continental scale to increase up to three standard deviations from the 1961-1990 mean by the end of the 21st century (Scherrer et al., 2005), such that winter 
2006-spring 2007 temperatures today considered as exceptional may become more and more commonplace. The frequency of late frosts should further decrease (Tebaldi et al., 2006), as should the risk of frost injury to canopy resulting in negative anomalies in the absorbed PAR fraction ( $\mathrm{Gu}$ et al., 2008). One may thus expect spring GPP to increase in the forthcoming decades.

In a recent analysis of the last two decades of atmospheric $\mathrm{CO}_{2}$ concentrations in the northern hemisphere, Angert et al. (2005) observed a trend towards an earlier resumption of spring $\mathrm{CO}_{2}$ uptake. They further reported no trend towards higher $\mathrm{CO}_{2}$ uptake for late summer data, and therefore concluded that warmer and drier summers tend to compensate for the increased uptake caused by warmer springs. Accordingly, a comparison of the spring $2007 \mathrm{C}$ uptake anomaly with the summer 2003 heat wave and subsequent drought (Ciais et al., 2005; Granier et al., 2007; Reichstein et al., 2007; Vetter et al., 2008), shows that if both extreme events were to occur in a single year, the occurrence of a summer heat wave and drought would indeed cancel out the benefits from spring warming in terms of net uptake (Fig. 10). Such a coincidence of warm springs (Scherrer et al., 2005) and warm and dry summers (Schär et al., 2004) is likely to increase during the 21st century. CASTANEA simulations show that warmer springs might even hasten the occurrence of drought, with early resumption of transpiration causing earlier depletion of soil water (conditional to low soil water recharge following transpiration onset; N. Delpierre, unpublished results), which would further compromise the beneficial effect of warm springs on the annual $\mathrm{C}$ balance.

\section{Acknowledgements}

We thank all researchers, engineers, technical assistants and students involved in the maintenance of the CARBOEUROPEIP study sites and database. We acknowledge the reviews, comments and suggestions from Prof. D. D. Baldocchi and two anonymous referees, which significantly helped strengthen the paper. ND receives a $\mathrm{PhD}$ grant from the French Ministère de $l^{\prime}$ Enseignement Supérieur et de la Recherche and the University of Paris-Sud.

\section{References}

Aber JD, Federer CA (1992) A generalized, lumped-parameter model of photosynthesis, evapotranspiration and net primary production in temperate and Boreal Forest Ecosystems. Oecologia, 92, 463-474.

Allard V, Ourcival JM, Rambal S, Joffre R, Rocheteau A (2008) Seasonal and annual variation of carbon exchange in an evergreen Mediterranean forest in southern France. Global Change Biology, 14, 714-725.
Angert A, Biraud S, Bonfils C et al. (2005) Drier summers cancel out the $\mathrm{CO}_{2}$ uptake enhancement induced by warmer springs. Proceedings of the National Academy of Sciences of the United States of America, 102, 10823-10827.

Arain MA, Black TA, Barr AG, Jarvis PG, Massheder JM, Verseghy DL, Nesic Z (2002) Effects of seasonal and interannual climate variability on net ecosystem productivity of boreal deciduous and conifer forests. Canadian Journal of Forest Research-Revue Canadienne De Recherche Forestiere, 32, 878-891.

Aubinet M, Chermanne B, Vandenhaute M, Longdoz B, Yernaux M, Laitat $E$ (2001) Long term carbon dioxide exchange above a mixed forest in the Belgian Ardennes. Agricultural and Forest Meteorology, 108, 293-315.

Aubinet M, Grelle A, Ibrom A et al. (2000) Estimates of the annual net carbon and water exchange of forests: the EUROFLUX methodology. Advances in Ecological Research, 30, $113-175$.

Baldocchi DD, Black TA, Curtis PS et al. (2005) Predicting the onset of net carbon uptake by deciduous forests with soil temperature and climate data: a synthesis of FLUXNET data. International Journal of Biometeorology, 49, 377-387.

Barr AG, Black TA, Hogg EH et al. (2007) Climatic controls on the carbon and water balances of a boreal aspen forest, 1994-2003. Global Change Biology, 13, 561-576.

Bergh J, McMurtrie RE, Linder S (1998) Climatic factors controlling the productivity of Norway spruce: a model-based analysis. Forest Ecology and Management, 110, 127-139.

Berninger F (1997) Effects of drought and phenology on GPP in Pinus sylvestris: a simulation study along a geographical gradient. Functional Ecology, 11, 33-42.

Black TA, Chen WJ, Barr AG et al. (2000) Increased carbon sequestration by a boreal deciduous forest in years with a warm spring. Geophysical Research Letters, 27, 1271-1274.

Blanken PD, Black TA, Neumann HH, den Hartog G, Yang PC, Nesic Z, Lee X (2001) The seasonal water and energy exchange above and within a boreal aspen forest. Journal of Hydrology, 245, 118-136.

Burba GG, McDermitt DK, Grelle A, Anderson DJ, Xu LK (2008) Addressing the influence of instrument surface heat exchange on the measurements of $\mathrm{CO} 2$ flux from open-path gas analyzers. Global Change Biology, 14, 1854-1876.

Chuine I (2000) A unified model for budburst of trees. Journal of Theoretical Biology, 207, 337-347.

Churkina G, Tenhunen J, Thornton P et al. (2003) Analyzing the ecosystem carbon dynamics of four European coniferous forests using a biogeochemistry model. Ecosystems, 6, 168-184.

Ciais P, Reichstein M, Viovy N et al. (2005) Europe-wide reduction in primary productivity caused by the heat and drought in 2003. Nature, 437, 529-533.

Damesin C, Ceschia E, Le Goff N, Ottorini JM, Dufrêne E (2002) Stem and branch respiration of beech: from tree measurements to estimations at the stand level. New Phytologist, 153, 159-172.

Davi H, Barbaroux C, Dufrêne E, Francois C, Montpied P, Bréda N, Badeck F (2008) Modelling leaf mass per area in forest canopy as affected by prevailing radiation conditions. Ecological Modelling, 211, 339-349.

Davi H, Dufrêne E, Francois C et al. (2006) Sensitivity of water and carbon fluxes to climate changes from 1960 to 2100 in 
European forest ecosystems. Agricultural and Forest Meteorology, 141, 35-56.

Davi H, Dufrêne E, Granier A, Le Dantec V, Barbaroux C, Francois C, Breda N (2005) Modelling carbon and water cycles in a beech forest Part II: validation of the main processes from organ to stand scale. Ecological Modelling, 185, 387-405.

De Pury DGG, Farquhar GD (1997) Simple scaling of photosynthesis from leaves to canopies without the errors of big-leaf models. Plant Cell and Environment, 20, 537-557.

Delpierre N, Dufrêne E, Soudani K, Ulrich E, Cecchini S, Boé J, François $C$ (in press) Modelling the interannual and spatial variability of leaf colouring for deciduous tree species in France. Agricultural and Forest Meteorology, doi: 1016/J.agr/ ormet.2008.11.014.

Dufrêne E, Davi H, François C, le Maire G, Le Dantec V, Granier A (2005) Modelling carbon and water cycles in a beech forest Part I: model description and uncertainty analysis on modelled NEE. Ecological Modelling, 185, 407-436.

Epron D, Le Dantec V, Dufrene E, Granier A (2001) Seasonal dynamics of soil carbon dioxide efflux and simulated rhizosphere respiration in a beech forest. Tree Physiology, 21, 145-152.

Falge E, Baldocchi D, Tenhunen J et al. (2002) Seasonality of ecosystem respiration and gross primary production as derived from FLUXNET measurements. Agricultural and Forest Meteorology, 113, 53-74.

Falge E, Tenhunen J, Aubinet M et al. (2003) A model-based study of carbon fluxes at ten European forest sites. In Ecological Studies, 163, 151-177.

Goulden ML, Munger JW, Fan SM, Daube BC, Wofsy SC (1996) Exchange of carbon dioxide by a deciduous forest: response to interannual climate variability. Science, 271, 1576-1578.

Granier A, Bréda N, Longdoz B, Gross P, Ngao J (2008) Ten years of fluxes and stand growth in a young beech forest in North Easthern France (Hesse Forest). Annals of Forest Science, 64, 704-716

Granier A, Reichstein M, Breda N et al. (2007) Evidence for soil water control on carbon and water dynamics in European forests during the extremely dry year: 2003. Agricultural and Forest Meteorology, 143, 123-145.

Grassi G, Vicinelli E, Ponti F, Cantoni L, Magnani F (2005) Seasonal and interannual variability of photosynthetic capacity in relation to leaf nitrogen in a deciduous forest plantation in northern Italy. Tree Physiology, 25, 349-360.

Grünwald T, Bernhofer C (2007) A decade of carbon, water and energy flux measurements of an old spruce forest at the Anchor Station Tharandt. Tellus B, 59, 387-396.

Gu L, Hanson PJ, Mac Post W et al. (2008) The 2007 eastern US spring freezes: increased cold damage in a warming world? Bioscience, 58, 253-262.

Hänninen H, Hari P (2002) Recovery of photosynthesis of boreal conifers during spring: a comparison of two models. Forest Ecology and Management, 169, 53-64.

Högberg P, Nordgren A, Buchmann N et al. (2001) Large-scale forest girdling shows that current photosynthesis drives soil respiration. Nature, 411, 789-792.
Jarvis P, Linder S (2000) Constraints to growth of boreal forests. Nature, 405, 904-905.

Keeling CD, Chin JF, Whorf TP (1996) Increased activity of northern vegetation inferred from atmospheric $\mathrm{CO}_{2}$ measurements. Nature, 382, 146-149.

Kolari P, Lappalainen HK, Hanninen H, Hari P (2007) Relationship between temperature and the seasonal course of photosynthesis in Scots pine at northern timberline and in southern boreal zone. Tellus Series B - Chemical and Physical Meteorology, 59, 542-552.

Konopka B, Yuste JC, Janssens IA, Ceulemans R (2005) Comparison of fine root dynamics in Scots pine and pedunculate oak in sandy soil. Plant and Soil, 276, 33-45.

Le Maire G, Davi H, Soudani K, Francois C, Le Dantec V, Dufrene E (2005) Modeling annual production and carbon fluxes of a large managed temperate forest using forest inventories, satellite data and field measurements. Tree Physiology, 25, 859-872.

Leinonen I (1996) A simulation model for the annual frost hardiness and freeze damage of Scots pine. Annals of Botany, 78, 687-693.

Lopez B, Sabate S, Gracia CA (2001) Annual and seasonal changes in fine root biomass of a Quercus ilex L. forest. Plant and Soil, 230, 125-134.

Luterbacher J, Liniger MA, Menzel A et al. (2007) Exceptional European warmth of autumn 2006 and winter 2007: historical context, the underlying dynamics, and its phenological impacts. Geophysical Research Letters, 34, doi: 10.1029/ 2007GL029951.

Mäkelä A, Hari P, Berninger F, Hanninen H, Nikinmaa E (2004) Acclimation of photosynthetic capacity in Scots pine to the annual cycle of temperature. Tree Physiology, 24, 369-376.

Mäkelä A, Pulkkinen M, Kolari P et al. (2008) Developing an empirical model of stand GPP with the LUE approach: analysis of eddy covariance data at five contrasting conifer sites in Europe. Global Change Biology, 14, 92-108.

Maignan F, Breon FM, Vermote E, Ciais P, Viovy N (2008) Mild winter and spring 2007 over western Europe led to a widespread early vegetation onset. Geophysical Research Letters, 35, doi: 10.1029/2007GL032472.

Medlyn BE, Robinson AP, Clement R, McMurtrie RE (2005) On the validation of models of forest $\mathrm{CO}_{2}$ exchange using eddy covariance data: some perils and pitfalls. Tree Physiology, 25, 839-857.

Myneni RB, Keeling CD, Tucker CJ, Asrar G, Nemani RR (1997) Increased plant growth in the northern high latitudes from 1981 to 1991. Nature, 386, 698-702.

Oliveira G, Peñuelas J (2000) Comparative photochemical and phenomorphological responses to winter stress of an evergreen (Quercus ilex L.) and a semi-deciduous (Cistus albidus L.) Mediterranean woody species. Acta Oecologica - International Journal of Ecology, 21, 97-107.

Öquist G, Huner NPA (2003) Photosynthesis of overwintering evergreen plants. Annual Review of Plant Biology, 54, 329-355.

Papale D, Reichstein M, Aubinet M et al. (2006) Towards a standardized processing of Net Ecosystem Exchange measured with eddy covariance technique: algorithms and uncertainty estimation. Biogeosciences, 3, 571-583. 
Paul KI, Polglase PJ, Smethurst PJ, O'Connell AM, Carlyle CJ, Khanna PK (2004) Soil temperature under forests: a simple model for predicting soil temperature under a range of forest types. Agricultural and Forest Meteorology, 121, $167-182$.

Piao SL, Ciais P, Friedlingstein P et al. (2008) Net carbon dioxide losses of northern ecosystems in response to autumn warming. Nature, 451, 49-U43.

Rambal S, Joffre R, Ourcival JM, Cavender-Bares J, Rocheteau A (2004) The growth respiration component in eddy $\mathrm{CO}_{2}$ flux from a Quercus ilex mediterranean forest. Global Change Biology, 10, 1460-1469.

Randerson JT, Field CB, Fung IY, Tans PP (1999) Increases in early season ecosystem uptake explain recent changes in the seasonal cycle of atmospheric $\mathrm{CO}_{2}$ at high northern latitudes. Geophysical Research Letters, 26, 2765-2768.

Reichstein M, Ciais P, Papale D et al. (2007) Reduction of ecosystem productivity and respiration during the European summer 2003 climate anomaly: a joint flux tower, remote sensing and modelling analysis. Global Change Biology, 13, 634-651.

Reichstein M, Falge E, Baldocchi D et al. (2005) On the separation of net ecosystem exchange into assimilation and ecosystem respiration: review and improved algorithm. Global Change Biology, 11, 1424-1439.

Repo T, Leinonen I, Wang KY, Hanninen H (2006) Relation between photosynthetic capacity and cold hardiness in Scots pine. Physiologia Plantarum, 126, 224-231.

Sala A, Tenhunen JD (1996) Simulations of canopy net photosynthesis and transpiration in Quercus ilex L. under the influence of seasonal drought. Agricultural and Forest Meteorology, 78, 203-222.

Sampson DA, Janssens IA, Yuste JC, Ceulemans R (2007) Basal rates of soil respiration are correlated with photosynthesis in a mixed temperate forest. Global Change Biology, 13, 2008-2017.

Sarvas R (1972) Investigations on the annual cycle of development of forest trees. I Active period. Communicationes Instituti Forestalis Fenniae, 76, 1-110.

Schär C, Vidale PL, Luthi D, Frei C, Haberli C, Liniger MA, Appenzeller C (2004) The role of increasing temperature variability in European summer heatwaves. Nature, 427, 332336.

Schaber J, Badeck FW (2003) Physiology-based phenology models for forest tree species in Germany. International Journal of Biometeorology, 47, 193-201.

Scherrer SC, Appenzeller C, Liniger MA, Schär C (2005) European temperature distribution changes in observations and climate change scenarios. Geophysics Research Letters, 32, doi: 10.1029/2005GL024108.

Schimel D, Churkina G, Braswell B, Trenbath J (2005) Remembrance of weather past: ecosystem responses to climate variability. In Ecological Studies, 177, 350-368.

Schmid HP, Grimmond CSB, Cropley F, Offerle B, Su HB (2000) Measurements of $\mathrm{CO}_{2}$ and energy fluxes over a mixed hardwood forest in the mid-western United States. Agricultural and Forest Meteorology, 103, 357-374.
Schwarz PA, Fahey TJ, Dawson TE (1997) Seasonal air and soil temperature effects on photosynthesis in red spruce (Picea rubens) saplings. Tree Physiology, 17, 187-194.

Sevanto S, Suni T, Pumpanen J et al. (2006) Wintertime photosynthesis and water uptake in a boreal forest. Tree Physiology, 26, 749-757.

Soudani K, Le Maire G, Dufrêne E, François C, Delpierre N, Ulrich E, Cecchini S (2008) Remote sensing of onset of greenup in deciduous broadleaf forests using Moderate Resolution Imaging Spectroradiometer (MODIS/Terra): evaluation and comparison with in situ observations over France. Remote Sensing of Environment, 112, 2643-2655.

Sparks JP, Campbell GS, Black RA (2001) Water content, hydraulic conductivity, and ice formation in winter stems of Pinus contorta: a TDR case study. Oecologia, 127, 468-475.

Stockfors J, Linder S (1998) Effect of nitrogen on the seasonal course of growth and maintenance respiration in stems of Norway spruce trees. Tree Physiology, 18, 155-166.

Suni T, Berninger F, Vesala $\mathrm{T}$ et al. (2003a) Air temperature triggers the recovery of evergreen boreal forest photosynthesis in spring. Global Change Biology, 9, 1410-1426.

Suni T, Rinne J, Reissell A et al. (2003b) Long-term measurements of surface fluxes above a Scots pine forest in Hyytiala, southern Finland, 1996-2001. Boreal Environment Research, 8, 287301.

Tang JW, Baldocchi DD, Xu L (2005) Tree photosynthesis modulates soil respiration on a diurnal time scale. Global Change Biology, 11, 1298-1304.

Tebaldi C, Hayhoe K, Arblaster JM, Meehl GA (2006) Going to the extremes. Climatic Change, 79, 185-211.

Thornton PE, Law BE, Gholz HL et al. (2002) Modeling and measuring the effects of disturbance history and climate on carbon and water budgets in evergreen needle leaf forests. Agricultural and Forest Meteorology, 113, 185222.

Vesala T, Suni T, Rannik U, Keronen P, Markkanen T (2005) The effect of thinning on surface fluxes in a boreal forest. Global Biogeochemical Cycles, 19, GB2001, doi: 10.1029/2004GB002316.

Vetter M, Churkina G, Jung M et al. (2008) Analyzing the causes and spatial pattern of the European 2003 carbon flux anomaly using seven models. Biogeosciences, 5, 561-583.

Welp LR, Randerson JT, Liu HP (2007) The sensitivity of carbon fluxes to spring warming and summer drought depends on plant functional type in boreal forest ecosystems. Agricultural and Forest Meteorology, 147, 172-185.

Wilson KB, Baldocchi DD (2000) Seasonal and interannual variability of energy fluxes over a broadleaved temperate deciduous forest in North America. Agricultural and Forest Meteorology, 100, 1-18.

Wilson KB, Baldocchi DD, Hanson PJ (2000) Spatial and seasonal variability of photosynthetic parameters and their relationship to leaf nitrogen in a deciduous forest. Tree Physiology, 20, 565-578.

Zha TS, Kellomaki Z, Wang KY, Ryyppo A, Niinisto S (2004) Seasonal and annual stem respiration of Scots pine trees under boreal conditions. Annals of Botany, 94, $889-896$. 
20 N. DELPIERRE et al.

Zhou L, Kaufmann RK, Tian Y, Myneni RB, Tucker CJ (2003) Relation between interannual variations in satellite measures of northern forest greenness and climate between 1982 and 1999. Journal of Geophysical Research-Atmospheres, 108, doi: 10.1029/2002JD002510.
Zweifel R, Zimmermann L, Zeugin F, Newbery DM (2006) Intraannual radial growth and water relations of trees: implications towards a growth mechanism. Journal of Experimental Botany, 57, 1445-1459. 